\title{
Hypertension and Cognitive Function
}

\author{
Thomas Olabode Obisesan, MD, MPH ${ }^{\star}$ \\ Division of Geriatrics, Department of Medicine, Howard University Hospital, 2041 Georgia \\ Avenue, NW, Washington, DC 20060, USA
}

\section{Keywords}

Aging; Memory; Dementia; Alzheimer's disease; Hypertension; Prevention; Treatment

\begin{abstract}
Advanced age is a key risk factor for dementia and hypertension (Fig. 1). By the year 2030, the number of individuals aged 60 years and older will reach 70 million in the United States alone. ${ }^{1-3}$ Fortunately, in addition to increased life expectancy, Americans are retaining vigor well into their 80s and beyond. But with longevity comes increased weakening of neurocognitive function. In this review, the author discusses the evidence indicating that primary and secondary prevention of hypertension may be an important public health goal in the United States for preventing or delaying cognitive loss.
\end{abstract}

Stroke and Alzheimer-type dementia increase at comparable rates with advancing age. Vascular disease is emerging as an important risk factor for dementia and Alzheimer disease (AD). In addition to age, diabetes, hypercholesterolemia, and presence of an apolipoprotein E4 (ApoE4) allele, all characterized by vascular pathology, hypertension is now considered an important risk factor for the sporadic, prevalent form of AD. ${ }^{4}$ Evidence from epidemiologic and prospective studies lends credence to this new paradigm: The Rotterdam population-based prospective study that examined approximately 8000 subjects aged 55 years and older for the frequency of lifetime risk for dementia and its subtypes, including $\mathrm{AD}$, showed an increase in the prevalence of atherosclerosis in vascular dementia and AD. ${ }^{5}$ Compilation of autopsy reports on $\mathrm{AD}$ brains indicates that approximately $60 \%$ to $90 \%$ of the cases exhibited variable cerebrovascular pathology synonymous with cerebrovascular disease (CVD). ${ }^{6,7}$ In $\mathrm{AD}$ cases ascertained by the presence of amyloid angiopathy, endothelial degeneration, and periventricular white matter lesions at autopsy, Van Nostrand and colleagues ${ }^{8}$ showed that approximately one-third had evidence of cerebral infarction. These reports indicate that CVD risk factors may also influence AD development.

From the CVD risk factors examined in many epidemiologic and clinical trials thus far, hypertension is recognized as the most consistent risk factor for stroke and, importantly, AD. ${ }^{9-13}$ Hypertension-related silent ischemic white matter increases with elevated blood pressure and is increasingly seen to coexist with AD. In addition to its role in vascular dementia, hypertension is now considered to have a causal relationship with dementia of the AD type. ${ }^{14,15}$ This belief is emphasized by prospective studies linking high blood pressure in midlife to dementia in late life. ${ }^{14,15}$

In addition to a causal relationship of hypertension with future cognitive decline, hypertension also contributes to known $\mathrm{AD}$ endophenotypes, such as brain volume. Specifically, systolic blood pressure (SBP) and pulse pressure (PPR) are associated with

(c) 2009 Elsevier Inc. All rights reserved.

*Corresponding author: tobisesan@ howard.edu. 
medial temporal lobe atrophy, which is a hallmark of $\mathrm{AD}$ (especially when they coexist with white matter changes) in individual with late-onset dementia. ${ }^{16}$ Although it was previously believed that hypertension-related cognitive decline was mediated directly through multiple brain infarcts, the new evidence indicates that hypertension can also act directly or synergistically with vascular disease to promote AD development.

Evidence about whether medication can attenuate hypertension-related cognitive decline is slowly emerging. Such studies range from epidemiologic (cross-sectional and prospective) studies to meta-analyses and clinical trials. Mechanisms by which hypertension influences cognitive function are also being investigated. Of significant interest is cerebral hypertension-induced vascular stiffness and consequent reduction in brain perfusion. Fortunately, treatment to reduce blood pressure can prevent arterial stiffness and improve cerebral perfusion, and thereby preserve cognitive dexterity. Conversely, excessive blood pressure reduction, especially in the aged, can cause cerebral hypoperfusion and cognitive loss. Therefore, identification of optimal blood pressure for best cognitive performance and reduction in $\mathrm{AD}$ risk is of considerable scientific, clinical, and public health interest.

Although consensus is lacking on what blood pressure levels offer the best beneficial effects on cognition, enough evidence exists to preliminarily guide treatment goals in older hypertensive patients. ${ }^{17-22}$ Using the Seventh Joint National Committee on Prevention, Detection, Evaluation, and Treatment of High Blood Pressure criteria, target blood pressure that is beneficial to cognition should be in the normal range $(<120 / 80 \mathrm{~mm} \mathrm{Hg})$ for (1) persons 75 years or younger, (2) persons 75 years or older with new-onset hypertension, and (3) persons with diabetes, irrespective of age. For persons 75 years or older who have chronic hypertension, blood pressure in the prehypertensive range $(120-139 \mathrm{~mm} \mathrm{Hg})$ is likely to be beneficial to cognition. Regardless of duration and history of hypertension, target blood pressure that is beneficial to cognition in persons 80 years or older should also remain in the prehypertensive range.

Medications used to achieve blood pressure control have significant cognitively beneficial effects that are independent of blood pressure levels. Dihydropyridine calcium channel blockers (DHP-CCBs), angiotensin converting enzyme (ACE) inhibitors, angiotensin receptor blockers (ARBs), and potassium-sparing diuretics exert cognitively beneficial effects. Although the evidence is hardly definitive, conversely, non-DHP-CCBs seem to have an opposing effect, possibly contributing to cognitive deterioration. These recommendations need to be substantiated in the future through double-blind placebocontrolled clinical trials.

Given the high prevalence of hypertension in the United States, substantial cognitive gains might be realized from the optimization of blood pressure. Even if hypertension only results in a moderately increased $\mathrm{AD}$ rate or overall dementia, better treatment and optimization of blood pressure can have a significant public health impact in primary prevention of $\mathrm{AD}$ and vascular dementia. ${ }^{10}$

In this review, the current understanding of the relationship of hypertension to cognitive health is discussed. The review focuses on evidence gathered from various study types, from cross-sectional studies to prospective and randomized controlled clinical trials, and posited mechanisms that mediate this relationship. 


\section{EVIDENCE LINKING HYPERTENSION TO COGNITIVE FUNCTION}

\section{Cross-sectional Studies}

Evidence-Hypertension is associated with diminished performance on tests of cognitive function. Initial support for this view came from epidemiologic studies. A few of these studies examined the relationship of blood pressure to cognitive loss in late life, ${ }^{23-26}$ and most reported beneficial effects. Although many such studies used varying degrees of blood pressure to define hypertension, a cross-sectional but rigorous epidemiologic study used a representative sample of the noninstitutionalized United States population to test the hypothesis that elevated blood pressure is associated with lower cognitive function. ${ }^{17} \mathrm{In}$ accordance with the sixth report of the Joint National Committee on Prevention, Detection, Evaluation, and Treatment of High Blood Pressure (JNC VI ${ }^{27}$ used by Obisesan and colleagues,${ }^{17}$ categories of blood pressure were defined as given in the next paragraph and in Table 1.

For the regression analysis used in the study, blood pressure was considered normal if SBP was from is $\leq 129 \mathrm{~mm} \mathrm{Hg}$ or diastolic blood pressure (DBP) is $\leq 85 \mathrm{~mm} \mathrm{Hg}$. These categorizations have since been revised in the seventh report of the Joint National Committee on Prevention, Detection, Evaluation, and Treatment of High Blood Pressure and even more so in the pending revised version. Results from this study indicate that in age groups 60 to 64, 65 to 69, and 70 to 74, optimal blood pressure ( $<120 / 80 \mathrm{~mm} \mathrm{Hg})$ was associated with best cognitive performance; severe hypertension was associated with the poorest performance in all age groups except the very old ( $\geq 80$ years), in whom the pattern was reversed, showing the poorest performance in the optimal blood pressure group and the best in the moderate hypertension group (Fig. 2). In analyses additionally adjusted for important covariates, increasing JNC-VI stage of hypertension associated with worsening cognitive performance compared with normal blood pressure at ages older than 70 years. This relationship appears less certain in the younger age group. From such studies having sufficient power to conduct age-stratified analysis, it is evident that the relationship of hypertension to cognitive function is susceptible to age effect.

In addition to reports from the third National Health and Nutrition Examination Survey (NHANES III) data, other epidemiologic studies have reported on the association of blood pressure with cognitive loss. ${ }^{11-13,28-32}$ A retrospective study of 89 patients with presenile dementia followed up by necropsy showed that approximately one-half of the 46 patients with $\mathrm{AD}$ and 3 of 16 mixed dementia subjects had systolic pressure greater than $140 \mathrm{~mm}$ Hg. ${ }^{28}$ Independent of resting clinical blood pressure, SBP and DBP reactivity also correlated with diminished performance on tests of immediate and delayed verbal memory and executive function. ${ }^{26}$ Together, this initial evidence supports the view that hypertension can attenuate cognitive reserve. These findings add significantly to growing evidence that uncontrolled hypertension contributes to dementia risk as the population ages.

Can hypertension treatment attenuate dementia risk?-The degree to which blood pressure is controlled in hypertensive patients is a critical determinant of related cognitive outcomes. ${ }^{25}$ Hypertensive patients whose blood pressure is poorly controlled have reduced performance on cognitive tests. Although the overall goal of the treatment of hypertension is to normalize blood pressure and reduce hypertension-related cognitive loss, cross-sectional data indicate that treatment of hypertension even without control can reduce its negative influence on cognition. Preliminary evidence supporting this view came from the NHANES III data showing that compared with persons with hypertension or with hypertension that is untreated and uncontrolled, treated but uncontrolled hypertension is associated with better cognitive performance even after discounting the effects of important covariates. ${ }^{17}$ In another study to examine the relationship of hypertension and blood pressure levels to 
cognition, individuals with high blood pressure failed to perform optimally on tests of nonverbal memory, motor speed, and manual dexterity, irrespective of prior diagnostic status. ${ }^{25}$ In this study, persons with hypertension who had poorly controlled blood pressure were most vulnerable to difficulties in tests on perceptuo-motor speed and manual dexterity compared with the control. ${ }^{25}$ Together, the cross-sectional evidence indicates that elevated blood pressure and hypertension cause cognitive loss when compared with optimal blood pressure or blood pressure in the normal range. Also, the maintenance of blood pressure in the normal range can attenuate hypertension-related cognitive loss (Fig. 3). These associations are independent of other common risk factors such as age, gender, ethnicity, education, income level, and history of stroke (Fig. 4).

Given these earlier observations, later epidemiologic work on the connection between blood pressure and cognitive function increasingly focuses on whether treatment with medication is beneficial in reducing hypertension-related cognitive loss. One such earlier report came from Cacciatore and colleagues, ${ }^{33}$ who observed that hypertension treated with medication related to better cognitive outcome in an Italian sample. Building on the observation of Cacciatore and colleagues, Richards and colleagues ${ }^{34}$ showed that hypertension treated with medication attenuated the related cognitive decline in a community sample of African Americans. As the evidence grew, interest also developed on whether the beneficial effect of treatment was because of a specific medication. In a study design similar to that of Richards and colleagues ${ }^{34}$ that used a geriatric practice community sample, Hajjar and colleagues ${ }^{35}$ provided additional insight by showing that the use of diuretics, $\beta$-blockers, and ACE inhibitors to treat hypertension associates with improved cognitive outcomes.

Jointly, this preliminary evidence indicates that cognitive outcomes in persons with hypertension whose blood pressure is controlled with medication and/or lifestyle alteration are similar to those in persons without hypertension; are slightly better than those in persons who underwent similar interventions but did not achieve blood pressure control; and are better than those in persons with hypertension not receiving treatment and whose blood pressure remained uncontrolled (see Fig. 3). ${ }^{17}$ These findings support the need for increased attention to preventative efforts and maintenance of blood pressure in the normal range to preserve cognitive function.

Negative studies-Although most cross-sectional treatment studies on the relationship of hypertension to cognitive loss found that treatment is mostly beneficial, studies reporting negative findings merit a brief discussion. For example, the East Boston cohort study found no relationship of hypertension to cognitive function in nondemented persons. ${ }^{36}$ In concordance with the East Boston study, a Canadian study on health and aging found no association of high blood pressure with cognitive decline or dementia. ${ }^{37}$ Given that years of hypertension is required for the development of related cognitive loss later in life, a nonsignificant association of elevated blood pressure with performance on cognitive measures in studies involving a younger age group is logical. Alternatively, a lower prevalence of neurocognitive loss and $\mathrm{AD}$ in those aged less than 65 may also explain the negative findings. For studies involving an older age group, inadequate characterization of the sample and other bias inherent in cross-sectional studies are competing explanations.

\section{Prospective Nonmedication Treatment Studies}

In general, longitudinal studies are advantageous in that they provide information on the temporal relationship and the duration and the effect of chronic hypertension on cognitive function, especially given that years of sustained elevated blood pressure may be required for its effects on cognitive function (Fig. 5). A few such studies examined the effect of blood pressure on subsequent developments of cognitive loss, and most found an association of 
hypertension in midlife with neurocognitive loss about 15 to 20 years later. ${ }^{38}$ For example, a significant association of hypertension with increased cognitive loss at follow-up was demonstrated in a sample of 700 patients with AD, who were followed for an average of 6 months. ${ }^{39}$ These nonmedication prospective studies support observations from the initial cross-sectional studies that demonstrated the harmful effect of hypertension on cognition.

To further delineate the role of vascular disease, in particular hypertension, in the pathogenesis of late-onset $\mathrm{AD}$, Skoog and colleagues ${ }^{13}$ analyzed the Longitudinal Population Study of 70-year-olds in Göteborg (Gothenburg), Sweden. In this study, persons with elevated blood pressure at about age 70 were more likely to have cognitive loss at ages 79 and 85 compared with controls. However, blood pressure differences between demented and nondemented groups tended to equilibrate in the years preceding the onset of actual cognitive loss, ${ }^{13}$ a finding that is independently supported by the work of Hanon and colleagues ${ }^{40}$ and Verghese and colleagues. ${ }^{41}$ This finding led to the consideration that hypotension may be a clinical prodrome of AD.

After the initial characterization of mild cognitive impairment (MCI) as the prodromal stage of $\mathrm{AD}$, its association with hypertension has also been a subject of debate. In a 21-year follow-up prospective Finnish population study to evaluate the impact of midlife elevated blood pressure on the subsequent development of MCI in the elderly, a tendency toward a significant relation between hypertension and the risk of MCI was observed. ${ }^{11}$ Such observations in MCI patients support findings in demented patients.

If indeed hypertension is a risk factor for $\mathrm{AD}$, it is reasonable to expect that it is also associated with important $\mathrm{AD}$ endophenotypes. To test this hypothesis, a population-based longitudinal study with 36 years of follow-up examined the relationship of midlife hypertension with later development of cognitive impairment, vascular dementia, and $\mathrm{AD}$ in Japanese-American men. ${ }^{31}$ In this study, elevated SBP in midlife is associated with important endophenotypes such as low brain weight and greater amounts of neuritic plaque in the neocortex and hippocampus. ${ }^{31}$ Also, elevated DBP related to greater numbers of neurofibrillary tangles in the hippocampus. ${ }^{31}$ These findings support earlier observations by Sparks and colleagues ${ }^{42}$ that increased blood pressure is associated with AD-related neuropathology in specific brain topologies central to the acquisition and storage of information.

Together, this evidence indicates that hypertension can directly increase dementia risk, and that the control of blood pressure can modify important endophenotypes and reduce dementia rates in persons with hypertension.

\section{Nonrandomized Controlled Studies on the Relationship of Hypertension to Cognitive Loss}

Given the array of cross-sectional and prospective data on the relationship of hypertension to cognitive loss, nonrandomized, controlled clinical studies are the next logical step. Few such studies have been completed, but many are underway.

Initial prospective studies focused primarily on treatment effects designed to normalize blood pressure without considerations for the class of medication used to achieve control, and most of them confirmed the beneficial effect as seen in the cross-sectional studies. For example, Guo and colleagues ${ }^{43}$ showed that the use of antihypertensive treatment is associated with a significant reduction in the risk of cognitive loss in later years. To determine whether baseline hypertension and antihypertensive treatment predicts cognitive decline in elderly individuals, a fairly large longitudinal population-based study of 1373 elderly individuals was conducted in Nantes (western France). In this 4-year follow-up study, persons with hypertension who received treatment were compared with a control 
group, and the treatment group had lower cognitive decline at follow-up. ${ }^{44}$ Another similarly designed study, but with a 5-year follow-up period of 1617 African Americans, observed a $38 \%$ reduction in cognitive decline in persons with hypertension treated with medication compared with untreated controls. ${ }^{45}$ These prospective studies add an additional layer of evidence to cross-sectional studies to support the role of hypertension in the development of AD.

Building on evidence from the initial, less specific treatment studies, including those suggesting that calcium plays a key role in brain homeostasis leading to AD, Yasar and colleagues ${ }^{46}$ investigated the relationship between the use of DHP- or non-DHP-CCBs with AD risk, using the Baltimore Longitudinal Study on Aging. From this study, an association between DHP-CCBs and reduced AD risk was observed, although not to a statistically significant level. In addition, the Cache County Study also showed that the use of potassium-sparing diuretic alone reduced the risk of $\mathrm{AD}$ by $\sim 47 \%$, which is a relatively large effect. ${ }^{47}$ Further, a 5-year follow-up study of a community sample of African Americans showed that antihypertensive and other medications affecting CVD risk factors is associated with $\sim 40 \%$ reduction in the risk of incident dementia. ${ }^{45}$ Using data from the Rotterdam study to examine the parallel relationship of hypertension to vascular dementia and $\mathrm{AD}$, a significantly beneficial effect of treatment with medication is associated with performance on cognitive tasks, although a less-than-optimal effect on AD was reported. ${ }^{48}$ Hanon and colleagues ${ }^{49}$ showed a $42 \%$ reduction in the risk of developing $\mathrm{AD}$ in persons with hypertension receiving medication, a finding that is also supported by Khatchaturian and colleagues ${ }^{47}$ using a large population-based sample of 3308 persons from the Cache County cohort. These provided early evidence that maintenance of blood pressure in the normal range by medication is cognitively advantageous.

Inconsistency of the relationship of blood pressure to cognition in older adults led to the realization that treatment studies must also be attentive to the extent of blood pressure control. Whether an aggressive reduction in blood pressure can augment cognitive loss in the elderly became a concern of many in the field. To address this question, the Heart Outcomes Prevention Evaluation study prospectively evaluated the effects of medications to treat hypertension and showed that the greatest reduction in blood pressure is associated with enhanced cognitive function in demented elderly. ${ }^{50}$ Conversely, few studies have documented a tendency for blood pressure to decrease in years immediately preceding dementia. ${ }^{13,40,41}$ The implication of these conflicting observations is that unknown factors comediate the relationship of blood pressure treatment and control to cognitive dexterity.

Because $\mathrm{AD}$ is a chronic disease, potentially requiring years of insult for phenotypic expression to occur, much attention was given to whether or not the duration of uncontrolled hypertension contributes to the earlier inconsistencies of hypertension-related cognitive loss. To address this question, the Honolulu Aging Study recently examined the effects of the duration of treatment of hypertension on subsequent cognitive loss. From this study, Peila and colleagues ${ }^{10}$ showed a $6 \%$ reduction in dementia risk for each additional year of treatment. Inherent in this finding is that the duration of treatment and control of hypertension, and perhaps the untreated and uncontrolled hypertension, are critical determinants of hypertension-related cognitive dexterity.

Collectively, these nonrandomized controlled trials add significantly to growing evidence that treatment of hypertension can delay or prevent associated cognitive loss; that blood pressure control is important; and that the duration of untreated and uncontrolled hypertension and the extent to which treatment and control are sustained play collective roles in the relationship between hypertension and cognitive dexterity. Importantly, these studies set the stage for randomized controlled trials and provide the momentum for a more 
detailed assessment of the differential class-effect of medication used to achieve blood pressure control.

\section{Randomized Controlled Trials}

Few large randomized controlled studies have added clarity to the relationship between the treatment and control of hypertension and future cognitive function as seen in the nonrandomized controlled studies. Although a few such studies failed to find significant differences between treatment groups, most reported that control of hypertension is beneficial to future cognitive stability.

Studies that reported a beneficial effect of treatment of hypertension not only added clarity, but also strengthened available evidence and the public health imperative for the treatment and control of hypertension. From the vascular dementia project, ${ }^{18}$ a 2 -year follow-up study of 2418 patients aged 60 and above with isolated systolic hypertension and randomized into treatment and control groups, a 50\% reduction in hypertension-related cognitive loss was found in the treatment group. From the same study, an additional 2 years of follow-up after unbinding the sample showed that early intervention and the long-term treatment and control of hypertension can significantly reduce the risk of related cognitive deterioration as the population ages. ${ }^{19}$ This observation, together with evidence from prospective but nonrandomized studies and from randomized but not placebo-controlled studies, supports the view that duration of untreated and/or uncontrolled hypertension is an important factor in the relationship between hypertension and future cognitive loss.

As evidence accumulated on the cognitively beneficial effects of treatment and control of hypertension, interest also grew on whether concomitant reduction in CVD risks and related phenotypes besides hypertension offers additional cognitive benefit. From the patient sample studied by Forette and colleagues, ${ }^{18,19}$ a concomitant reduction in the rates of $\mathrm{AD}$ and vascular and mixed dementia was observed at 2- and 4-year follow-up points, suggesting that treatment and/or control of hypertension can also reduce AD and vascular- and mixed dementia-specific risks. Observation of $12 \%$ to $19 \%$ reduction in the risk of dementia and cognitive loss, respectively, in the Perindopril Protection Against Recurrent Stroke Study trial using perindopril (an ACE inhibitor) with or without indapamide in the treatment versus control groups ${ }^{20}$ adds credence to earlier observations by Forette and colleagues. ${ }^{18,19}$ Because hypertension in this sample was defined as an SBP of $160 \mathrm{~mm} \mathrm{Hg}$ or higher and a DBP of $90 \mathrm{~mm} \mathrm{Hg}$ or higher, treatment targets may have been insufficient for optimal cognitive benefits. These findings indicate that concomitant reduction in other CVD risk factors is incidental to the treatment of hypertension and may augment the benefits from hypertension treatment and/or control. Given that few other CVD risk factors are implicated as $\mathrm{AD}$ risk, it remains possible that reduction in these other risk factors can mechanistically explain the beneficial effects of treated but uncontrolled hypertension on cognition. As such, the HOPE trial, a randomized placebo-controlled study of 9297 patients with vascular disease or diabetes together with an additional CVD risk, followed up participants for an average of $\sim 4.5$ years. ${ }^{21}$ In this study, a significant $41 \%$ reduction in stroke-related cognitive decline was observed in the ACE inhibitor-treated group compared with the placebo group.

Conclusions from meta-analysis of the randomized placebo-controlled studies affirm the usefulness of treatment and control of hypertension in preventing future CVD- and ADrelated cognitive decline in persons with hypertension. ${ }^{51,52}$ In addition to blood pressure control, a concomitant improvement in other CVD risk markers during such treatment offers additional neuroprotection beyond what is provided by the control of blood pressure alone.

Negative results-Whereas most randomized controlled trials confirmed the idea that cognitive loss is associated with untreated hypertension, a few found no significant effect. 
For example, a 54-month follow-up study of 2584 older persons with hypertension treated with diuretics or $\beta$-blockers showed no difference between the treatment and control groups. ${ }^{53}$ Building on the work of Prince and colleagues, ${ }^{53}$ the Systolic Hypertension in the Elderly Program is a 5-year follow-up study that compared the incidence of dementia in a group of persons with hypertension treated with diuretics and/or $\beta$-blockers with placebo. Although the incidence of dementia tended to be lower in the treatment group, the difference did not reach statistical significance. Using 3.7-year follow-up data from the study on cognition and prognosis in the elderly, Lithell and colleagues ${ }^{54}$ found no association between the groups of persons with hypertension treated with ARB and diuretic compared with controls. Also, while McGuinness and colleagues ${ }^{55}$ showed $\sim 11 \%$ reduction in the risk of dementia in patients without earlier cerebral vascular accident (CVA), the difference was not significant. Also, the hypertension in the very elderly sub-study trial used a doubleblind, placebo-controlled study to assess whether treatment of hypertension in patients aged 80 years and above would reduce the incidence of dementia, vascular dementia, and AD. Despite this tendency toward a beneficial effect, a nonsignificant hazard ratio of 0.86 was found in the study. Notably, the target blood pressure of $150 \mathrm{~mm} \mathrm{Hg} \mathrm{SBP}$ in the study may have been suboptimal for a cognitively beneficial effect of treatment. ${ }^{22}$ For many of these negative studies, the extent to which the duration of exposure (for the untreated or the treated whose hypertension went uncontrolled) contributed to the cognitive outcome was not considered.

Whereas studies supporting the idea that the treatment and control of hypertension would be beneficial for minimizing future cognitive loss are hardly definitive, most of them reported a beneficial effect, and negative observations are in the minority. Together, they provide insight into the effects of blood pressure treatment and control on future cognitive function, and whether the choice of medication to treat elevated blood pressure is important to the cognitively beneficial effects.

\section{Type of Antihypertensive Medication and Cognitive Benefit}

Although conclusions from treatment studies indicate mostly beneficial effects, studies reporting negative results cannot be ignored. Explanations for negative findings have dwelled largely on study design, sample size, duration of exposure to hypertension, and the extent to which control with treatment was sustained. However, it is increasingly recognized that choice of antihypertensive medication may have differential cognitively beneficial effects. To address this question, the effect of medications affecting the posited mechanisms by which hypertension exerts its cognitively beneficial effects was recently examined. Such medications include mostly ACE inhibitors and ARBs. Medications such as CCBs considered to not favorably affect cognitive homeostasis were also examined.

Support for the cognitively beneficial effect of ACE inhibitors came from the work of Gard, ${ }^{56}$ who demonstrated that ACE inhibitors have moderate effects on cognitive reserve, but that the ARB losartan has even significantly better beneficial effect on memory. Increasingly, white matter hyperintensity is observed to coexist with AD. Users of antihypertensive medications such as CCBs or loop diuretics have more severe white matter hyperintensity on MRI and worse performance on modified 3MS than users of $\beta$-blockers. ${ }^{57}$ Together, the evidence indicates that ACE, and to a greater extent ARB, can augment the cognitively beneficial effect of blood pressure control in persons with hypertension.

Not all medications used to achieve control of blood pressure have cognitively beneficial effects. Building on the potential adverse cognitive effects associated with the use of CCBs in the elderly in cross-sectional studies, Maxwell and colleagues ${ }^{58}$ examined prospectively the association of the use of CCBs and that of other antihypertensive drugs with cognition. From this study, the users of CCBs were significantly more likely than others to experience 
cognitive decline, ${ }^{58}$ indicating that CCBs are associated with adverse cognitive outcomes. In an attempt to further crystallize the effects of the CCBs, Yasar and colleagues ${ }^{46}$ showed that, although the DHP-CCBs tend to be beneficial, the non-DHP-CCBs actually propagate cognitive deterioration.

Collectively, these reports indicate that medications to treat hypertension have class effects - some exert beneficial effects; others do not. Antihypertensives having the ability to cross the blood-brain barrier and modify the renin-angiotensin-aldosterone system (such as perindopril or losartan) or brain calcium metabolism (nitrendipine) provide additional defense against cognitive loss beyond that provided by blood pressure control alone. Conversely, centrally acting sympatholytic agents and non-DHP-CCBs appear to promote cognitive loss. The beneficial effects of ARB suggest that angiotensin receptor ligands may have potential in the prevention or even reversal of dementias, specifically of the AD type.

\section{SPECIAL CONSIDERATION ON THE ASSOCIATION OF HYPERTENSION WITH COGNITIVE FUNCTION}

\section{Low Blood Pressure and Memory Function}

Although the investigation of the relationship of blood pressure to cognitive decline has focused largely on hypertension, the evidence also indicates that excessively low blood pressure can promote cognitive decline. Evidence from the NHANES III data suggests that low blood pressure exerts a negative cognitive consequence, especially in the very old (>80 years). Other published results assert increased incidence of dementia and $\mathrm{AD}$ in persons with low SBP or DBP, respectively. Because the duration of hypertension can modify blood pressure-related cognitive outcome, understanding of this relationship is critically important. ${ }^{41,59,60}$ In addition to cross-sectional evidence, a few studies with sufficient follow-up time on the relationship of low blood pressure to cognitive decline are briefly discussed. From the Kungsholmen project, Qiu and colleagues ${ }^{60}$ showed that low DBP $(<70$ $\mathrm{mm} \mathrm{Hg}$ ) in $\sim 7$ years before dementia diagnosis, while baseline evidence of cognitive function was controlled for, was associated with increased risk of dementia and AD. This finding was even stronger among those undergoing treatment for hypertension. Similarly, Qiu and colleagues ${ }^{61}$ showed that $\mathrm{a} \geq 15 \mathrm{~mm} \mathrm{Hg}$ drop in SBP in subjects whose baseline SBP is less than $160 \mathrm{~mm} \mathrm{Hg}$ predicted dementia and AD, especially in those suffering from vascular disorders such as CVA and diabetes. The 3-year follow-up data from the Gothenburg and Rotterdam studies also support the inverse association of SBP and DBP with dementia risk among those undergoing treatment for hypertension. ${ }^{62}$ A long-duration follow-up study, the Bronx Aging Study on community-dwelling volunteers, showed that low DBP ( $<70 \mathrm{~mm} \mathrm{Hg})$ is associated with a nearly two-fold increase in dementia risk and AD. Persistently low DBP is associated with even greater risk of dementia and cognitive decline. ${ }^{41}$

Although the exact levels of cognitively beneficial blood pressure are yet to be quantified, a discussion of the effects of low blood pressure on cognition is incomplete without recognition of the age factor. Although treatments to lower blood pressure can enhance cognition, an aggressive reduction in blood pressure must be approached with caution, given the unanticipated negative cognitive consequences in the very old. Whether relatively low blood pressure is a complication of dementia of the AD type or whether it merely predisposes a subpopulation to an increased dementia risk needs further clarification.

Because chronic hypertension-induced endothelia-hyalinosis may compromise cerebral perfusion, maintenance of blood pressure in the optimal range in chronically hypertensive elderly may bring less than optimal benefit. It may further compromise adaptive physiologic mechanisms to enhance cerebral perfusion and combat cerebral oxygen deprivation in the 
very old. In addition to the considerations for comorbid conditions in the treatment of hypertension, the control of blood pressure in the very old must consider age and severity and duration of hypertension to optimize the benefits of such a treatment.

\section{Pulse and Blood Pressure: Non-Linear Relationship to Cognitive Function}

Similar to what was found in studies that examined the relationship of stages of hypertension to cognitive outcomes, ${ }^{17}$ the relationship of PPR to cognitive reserve is predominantly nonlinear, and it is moderated by age and education. In addition to the evidence from the NHANES data, others have reported that low pulse and blood pressure can promote cognitive loss. ${ }^{63,64}$ A significant association of PPR with increased AD risk was demonstrated in a Korean group, although with much smaller sample size than in the NHANES. ${ }^{63}$ A finding not observed in the Korean study, but supported by published reports from Qiu and colleagues ${ }^{65}$ is a U-shaped relationship of PPR with cognitive performance.

Higher and lower tertiles of PPR paralleled cognitive decline in a sample of 256 AD patients examined in this study. This finding is in concordance with results from Morris and colleagues ${ }^{66}$ who reported a nonlinear relationship of hypertension with cognitive function using a biracial community sample. Also, from the Baltimore Longitudinal Study of Aging, Waldestein and colleagues ${ }^{64}$ demonstrated a nonlinear relationship of hypertension with poor cognitive function. This evidence indicates that the relationship of PPR to cognitive dexterity is fairly complicated and nonlinear.

Similar to the relationship between PPR and cognitive performance, elevated blood pressure is nonlinearly related (U-shaped) to performance on cognitive tasks, especially in the old ( $\geq 70$ years). This effect is most significant in the very old (see Fig. 4). Although the exact understanding of this relationship needs further clarification, it is not known whether there is a threshold beyond which an increase in blood pressure can overcome the barrier to brain perfusion created by hypertension-induced endothelial dysfunction and cerebral autoregulatory mechanisms. Alternatively, selective CVD-related mortality in persons with severe hypertension offers a competing explanation. Collectively, this evidence suggests that hypertension is an important dementia risk factor, that the relationship between the two is nonlinear, and that it remains even after discounting the contribution of other important risk factors. Even if hypertension results in mild worsening of cognitive loss, and the early treatment and control of hypertension result in a slight reduction of dementia risk, the benefit of an early intervention can be substantial, given the high prevalence of hypertension and the growing magnitude of dementia as the United States population ages.

\section{MECHANISM BY WHICH HYPERTENSION AFFECTS COGNITIVE FUNCTION}

\section{Overview}

Although cerebral hypoperfusion and chronic oxygen deprivation appear central to the effects of hypertension on neurocognition and $\mathrm{AD}$ pathology, understanding of the exact mechanism mediating this relationship is a work in progress. Experimental investigations including animal studies provided the first line of evidence supporting several of the proposed mechanisms. Chronic hypertension-induced upregulation of vascular pathology appears to exert the most significant effects. For example, an important dementia precursor could be the unfavorable effects of hypertension on microvascular degeneration that alters cerebral endothelium. Second, hypertension-induced proliferation of smooth muscle cells, basal lamina alterations, luminal narrowing, endothelia-hyalinosis, and fibrosis have been reported to cause hypoperfusion and chronic cerebral oxygen insufficiency ${ }^{67}$ and deranged glucose homeostasis such as in AD. Associated alteration in neurovascular coupling, complex autoregulatory system and consequent cerebral hypoperfusion often complicate these vascular changes. Third, the ACE, RAS, and nitric oxide (NO) pathways are central to 
the pathogenesis of hypertension and have been reported to mediate some of these vascular changes in persons with chronic hypertension. Also, direct independent effects of the ACE, RAS, and NO systems on neurocognition and $\mathrm{AD}$ pathology are increasingly recognized.

Endothelia-hyalinosis, reduced vascular compliance and fibrosis, neurovascular coupling, complex autoregulatory system, and cerebral hypoperfusion, independently or acting synergistically, appear to mediate the effects of chronic hypertension on neurocognition and AD pathology (Fig. 6). Indeed, these vascular changes may impair the ready flux of important biochemical and synaptic transmission. Alternatively, changes in the blood-brain barrier may result in increased vascular permeability, protein extravasations in the brain parenchyma, leading to amyloid $\beta(\mathrm{A} \beta)$-protein accumulation. ${ }^{68}$ It is also possible that independent but similar causal mechanisms may be responsible for hypertension and cognitive loss and AD pathology.

\section{Hypertension and Cerebral Hypoperfusion}

Cerebral perfusion and chronic cerebral oxygen insufficiency-Hypertension, cerebral hypoperfusion, and chronic cerebral oxygen insufficiency are causally linked to neurodegeneration. A complex, but delicate autoregulatory system guides cerebral blood flow. Derangement of this autoregulatory system, such as imposed by hypertension, causes cerebral hypoperfusion and significantly alters neurotransmission essential to cognitive health. These changes, acting in concert with endothelial dysfunction in the small cerebral vessel, result in chronic cerebral oxygen deprivation and increased susceptibility to hypoxia.

The relevance of oxygen deprivation to proper neuronal and cognitive function was demonstrated by Lukiw and colleagues. ${ }^{69}$ It was shown that in neural cell culture and in the hippocampus using in vivo models, cyclooxygenase- 2 and presenile- 1 are induced after only about 5 minutes of hypoxia. ${ }^{69,70}$ From the available evidence, it is reasonable to conclude that cerebral hypoperfusion is an important common pathway by which vascular pathology exerts its deleterious effects on neurocognitive function. The ensuing discussion focuses on hypertension-related vascular derangements and their relationship to cerebral hypoperfusion.

Cerebral hypoperfusion and cognition-Results from studies in humans support a causal role for cerebral hypoperfusion in the pathogenesis of hypertension-related cognitive loss. Several of these studies also demonstrated a significant relationship between cerebral hypoperfusion and $\mathrm{AD}$ phenotype. ${ }^{71-73}$ Tsolaki and colleagues ${ }^{74}$ reported that cerebral hypoperfusion is significantly associated with performance on the Cambridge Cognitive Examination. In support of the relationship between cerebral blood flow (CBF) and $\mathrm{AD}$ endophenotypes, Ueda ${ }^{75}$ established that left posterior temporal regional CBF predicted performance on the clock drawing test. Independently, Jagust and colleagues, ${ }^{76}$ Tsolaki and colleagues, ${ }^{74}$ and Ushijima and colleagues ${ }^{77}$ confirmed the link between performance on the mini mental state examination (MMSE) and hypoperfusion in the frontal, parietal, and temporal cortex. In the study by Ushijima and colleagues, attention and calculation showed a correlation with decline in CBF in the frontal cortex, whereas orientation and recall associated with attenuated $\mathrm{CBF}$ in posterior brain regions. Others have also reported on the relationship of $\mathrm{CBF}$ with $\mathrm{AD}$ endophenotypes and the rate of cognitive decline in $\mathrm{AD}$. Nagahama and colleagues ${ }^{78}$ showed that reduced CBF in the right posterodorsal, anterior, and superior prefrontal cortex and the inferior parietal cortex was most pronounced in the category of AD patients with rapidly progressing cognitive loss. It therefore appears that cerebral hypoperfusion has an etiologic role in the pathogenesis of $\mathrm{AD}$.

In addition to the direct effect of hypertension, changes in PPR contribute to changes in cerebral hemodynamics. Increased PPR is a marker of increased arterial stiffness and widespread atherosclerosis, ${ }^{79-81}$ both of which can cause cerebral hypoperfusion. 
Conversely, low PPR correlates with decreased blood ejection, low stroke volume, and decreased cerebral perfusion pressure. Because low and high PPR can cause cerebral hypoperfusion and chronic cerebral oxygen deprivation, they also likely contribute to hypertension-related cognitive loss.

\section{Hypertension, Neurovascular Coupling, and Cognition}

Hypertension-induced changes in neurovascular coupling have been suggested to associate with neurodegeneration. Such deranged processes may act through three important mechanisms: (1) changes in cerebrovascular function and structure, altering brain hypoperfusion; (2) alteration in vascular reactivity and activation of $A \beta$; and (3) other mechanisms yet to be fully characterized.

At the structural level, it is well established that cerebrovascular structures are significantly altered in $\mathrm{AD} .{ }^{82}$ Such alterations include reduction in the number of microvessels, flattening of endothelial cells, and degeneration of vascular smooth muscle. ${ }^{82}$ In uncontrolled, longstanding hypertension, alteration in the vascular microcirculatory system results in neurovascular coupling and reduced brain perfusion. Such reduction in resting CBF has been suggested to attenuate the neuronal-related activation of compensatory increase in CBF. ${ }^{83}$

Newly emerging evidence suggests that hypertension-induced vascular changes can also directly promote $A \beta$ pathology. Although in-depth understanding of this process is still evolving, it has been reported that by attenuating the activation of neuronal-related increase in compensatory $\mathrm{CBF}$, neurovascular coupling directly up-regulates $\mathrm{A} \beta$ formation. Significant dysregulation of cerebral circulation in mouse models of $A D$, mutated to overexpress APP and increase A $\beta$ levels, supports the neurovascular coupling derangement hypothesis. ${ }^{83}$ Also, attenuation of endothelia-dependent vascular response while reactions to vasoconstriction are exaggerated have also been found to exacerbate the upstream effects of hypertension-related dysregulation. ${ }^{84,85}$ Presence of such alterations in vascular reactivity in isolated vessel of normal mouse exposed to $A \beta_{1-40} 85,86$ further supports the role of neurovascular coupling and strengthens the dysregulation hypothesis.

Other direct mechanisms may mediate the relationship of hypertension-related alteration in neurovascular coupling to $\mathrm{AD}$. For example, vasoconstriction can alter the transfer of nutrients and oxygen supply to the brain. Less than optimal CBF may also alter $\mathrm{A} \beta$ trafficking across the blood-brain barrier ${ }^{87}$ and reduce $A \beta$ clearance while promoting its accumulation in the brain. Independently, reduced CBF may attenuate synthesis of protein central to optimal neuronal function and cognitive plasticity.

Changes in cerebrovascular function and structure and brain hypoperfusion, alteration in vascular reactivity and activation of $\mathrm{A} \beta$, and other processes yet to be fully characterized are important mechanisms mediating the relationship of hypertension to cognitive health.

\section{Hypertension, Cerebral Autoregulation, Hypometabolism, and Cognition}

A distinct component of the cerebral autoregulatory system is linked to cerebral metabolism. During neuronal activity, an increase in oxygen usage is followed by immediate increase in $\mathrm{CBF} .{ }^{88}$ Such an increase in CBF maintains a near-constant oxygen and glucose delivery to the brain, therefore maintaining cerebral metabolism. Given this, an increase in oxygen and glucose uptake often indicates enhanced cerebral metabolism. ${ }^{89}$ Because changes in cerebral metabolism can be deduced from regional cerebral perfusion, cerebral perfusion is used as an indicator of neuronal activity in neuroimaging studies. ${ }^{83,90}$ An important protective system ensures near-constant CBF through autoregulation and prevents significant fluctuation in cerebral perfusion. ${ }^{83,91,92}$ A compensatory, autoregulatory arterial-arteriolar bed dynamically adjusts the capacity and compliance of its vessels in response to changes in 
cerebral blood perfusion pressure (CPP) by dilating when CPP drops and constricting when CPP increases. ${ }^{93}$ The ultimate goal of this process is to optimally deliver oxygen and glucose to brain tissue. In summary, hypertension can alter brain perfusion, impair oxygen and glucose delivery to the brain, and alter brain metabolism in AD.

Hypertension-related cerebromicrovascular pathology is central to the cerebral hypoperfusion in AD brain. ${ }^{94-98}$ Similar to the effect of hypoperfusion on brain glucose homeostasis, a diminution in cerebral metabolism that results in decreased CBF can also exert negative cognitive effects. ${ }^{99}$ Although consensus is lacking on whether reduced cerebral perfusion in $\mathrm{AD}$ brain precedes cerebral hypometabolism, given that years of hypertension and reduced cerebral perfusion are required for evident cognitive loss and cerebral hypometabolism, ${ }^{98}$ it is reasonable to suggest that hypoperfusion in $\mathrm{AD}$ may also precede cerebral hypometabolism. In support of this view, Warkentin and colleagues ${ }^{100}$ consistently observed diminution in cerebral glucose metabolism in the temporoparietal cortex of $\mathrm{AD}$ brain, whereas varying degrees of hypoperfusion were concomitantly observed in the frontal and occipital cortex of different AD patients. Late-onset AD patients demonstrating significant brain hypometabolism have attenuated perfusion in the hippocampal-amygdaloid complex, the anterior and posterior cingulate, and the anterior thalamus. ${ }^{101,102}$ Regardless of the directionality of the association, collectively, the evidence mostly suggests that reduced CBF is linked to deranged cerebral glucose homeostasis, a hallmark of AD. Notably, significant evidence indicates that hypertension has an etiologic role in the development of cerebral hypoperfusion.

\section{Hypertension, Brain Renin-Angiotensin System, Angiotensin-Converting Enzyme, and Cognition}

Angiotensin II is a key factor in the pathogenesis of hypertension. ${ }^{103}$ Also, the RAS system exerts a significant effect on cognitive function. Although this effect may be partly mediated through hypertension-related vascular dysfunction, available evidence also indicates that the RAS system can directly influence AD pathology in the brain. However, whether elevated blood pressure directly mediates RAS-related memory loss or RAS merely shares a common risk factor with hypertension and $\mathrm{AD}$ is yet to be ascertained. Nonetheless, the understanding of this relationship merits a brief discussion in this review.

More than 100 years have passed since the first component of the RAS, renin, isolated from the kidney extracts, was observed to induce vasopressor response in rabbits by Tiegerstedt in 1898. The RAS is a complex enzymatic pathway generating several active peptides that controls fluid homeostasis, blood pressure, hormone secretion, and behavioral and cognitive responses. ${ }^{104,105}$ Although an active component of the RAS such as angiotensin II does not cross the blood-brain barrier, peripheral RAS can directly influence cerebral regions such as the circumventricular areas that lack the blood-brain barrier. Beyond the peripheral effects of RAS in such a brain region, an independent RAS also exists in the brain. The effects of RAS and ACE on the cognitive process are therefore exerted through several pathways: effects on blood pressure, direct effects on neurotrophic processes important to efficient learning and memory, direct effect on aggregation of $A \beta$, and effects on the cholinergic system.

Although evidence on the role of the RAS in learning and memory is contradictory, most studies support the view that angiotensin is harmful to cognitive processes. ${ }^{106}$ The relationship of ACE to vascular disease and pathologies is one important way by which RAS exerts its effects on neurocognition. ${ }^{107}$ The brain's RAS system regulates sympathetic activity and baroreflexes and contributes to neurogenic hypertension. ${ }^{108}$ Higher ACE activity in plasma is closely associated with higher prevalence of hypertension, ischemic heart disease and lacuna strokes, and cognitive loss. ${ }^{109}$ These associations indicate that a 
significant part of the effects of ACE on cognition may be mediated through its effects on blood pressure.

Although the RAS system may exert significant effect through its influence on blood pressure, much evidence also exists on additional, but direct and independent, effects on cognitive processes. In addition to its role in the modulation of blood pressure, RAS also exerts multiple additional functions in the brain, including processes of sensory information, learning, and memory. ${ }^{106,110}$ Inhibitors of RAS, particularly ACE inhibitors and angiotensin II receptor antagonists, have been demonstrated to have potential neurotropic effects in various learning and memory paradigms. ${ }^{111}$ Experimental studies also indicate that chronic long-term inhibition of the RAS can prevent most of the deleterious effects caused by aging in the cardiovascular system and the brain in normal mouse and rat. ${ }^{112}$ Angiotensin II antagonist injection before and after a conditioned avoidance test facilitated learning and retention. ${ }^{12,113}$ It acts directly on central RAS receptors to enhance associative memory and learning, possibly with a differential effect on acquisition, storage, and recall. ${ }^{113}$ In support of earlier findings, Gard and colleagues ${ }^{106}$ demonstrated that ACE inhibitors have cognitive enhancing effects, and they enhance learning in rats. This evidence supports the view that the RAS system, which is central to the pathogenesis of hypertension, may also have an additional but important role in cognitive processing that is independent of its effects on blood pressure.

At the molecular levels, and independent of hypertension effect, RAS directly promotes aggregation, deposition, and fibril formation of neurotoxic $\mathrm{A} \beta$ in the AD brain. ${ }^{114}$ If RAS were a promoter of $\mathrm{AD}$ pathology, an opposing effect would be expected with $\mathrm{ACE}$ inhibitor. Indeed, $A C E$ inhibitors directly reduce $A \beta$ aggregation, attenuate $A \beta$ fibril formation, and prevent neuronal cell death from $A \beta$-induced neurotoxicity, ultimately reducing susceptibility to $\mathrm{AD} .{ }^{114}$ These indicate that RAS can directly promote $\mathrm{A} \beta$ formation, and that this effect is attenuated by ACE inhibitor.

The cholinergic system is involved in cognitive processes. A direct link of RAS and ACE to the cholinergic system has also been established. Because angiotensin II can have an inhibitory effect on acetylcholine release, it is believed that inhibitors of this biochemical process, such as ACE inhibitors, can enhance cognition through the release of acetylcholine. Supporting this view, Denny and colleagues ${ }^{115}$ showed that angiotensin II blocked longterm potentiation in the hippocampus and amygdala. Therefore, angiotensin II receptor blockers would be expected to have effects on cognitive processes that are similar to those of ACE inhibitors. It is recommended that future studies on the relationship of angiotensin II remain cognizant of its complex relationship with learning so that they do not misinterpret any apparent inconsistencies that show an inhibitory action at low doses but an enhancing effect at higher doses. Failure to recognize such differential relationships may slow scientific advancement in the understanding of this relationship. ${ }^{116}$

\section{Hypertension, Endothelial NO, and Cognitive Function}

Dysfunctionality of NO metabolism is central to the pathogenesis of hypertension and cerebral hypoperfusion that occurs in $\mathrm{AD} .{ }^{117}$ Nitric oxide contributes to the functional vascular changes under pathologic conditions, such as those observed in hypertension. ${ }^{118}$ Nitric oxide derived from vascular eNOS is involved in vascular tone, blood pressure modulation, vascular homeostasis, and ultimately cerebral perfusion. Because cerebral autoregulation is mediated by NO, an efficient eNOS system attenuates atherosclerosis and thrombosis and improves blood flow by lowering stress on the blood vessel walls. By doing so, NO protects the endothelial cell function, which is an important mediator of hypertension-related vascular dysregulation and dysfunctionality. ${ }^{119}$ 
Longstanding, untreated, and uncontrolled hypertension acting in concert with the NO system results in cerebral hypoperfusion. Through the disturbance of basal NO levels, chronic hypertension causes alteration in the endothelium and induces vascular injury. ${ }^{120}$ As cerebral perfusion decreases below a certain critical point, eNOS attempts to maintain vascular homeostasis by upregulating NO. ${ }^{94-97}$ When this attempt fails, NO deregulation ensues. Together with hypoperfusion, the resulting damage to the endothelium impairs glucose flux to the brain, ${ }^{121}$ a process that heralds the development of cognitive loss. Independent of hypoperfusion-related dysfunctionality of the NO system, hypertensionrelated deterioration in $\mathrm{NO}$ homeostasis and associated oxidative alterations also directly contributes to neuronal cell death, such as that seen in $\mathrm{AD} .^{122-124}$

Evidence is also growing to suggest that hypertension-related dysfunction in the NO system acts synergistically with the cholinergic receptors to directly promote AD pathology. In conscious rat, Nakajima and colleagues ${ }^{126}$ showed that the activation of nicotinic acetylcholine receptors with consequent neural vasodilatation contributes to an increase in $\mathrm{CBF}$ and NO production in the hippocampus. ${ }^{125,126}$ Implicit in this finding is that basal forebrain and medial septal cholinergic neurons may have direct projections onto the eNOSpositive interneuron with the possibility of important access to vasodilatation mechanism through the release of NO. Evidently, the entire cortical system, including the hippocampus, is densely innervated by a fine network of eNOS-positive fibers, which derived its origin from scattered eNOS-positive inter-neuron. The study by Moro and colleagues, ${ }^{127}$ which supports the inference from the work of Nakajima and colleagues, ${ }^{126}$ demonstrates the colocalization of NOS and muscarinic receptors in interneurons in neocortical regions projecting onto cerebral microvessels. Cholinergic denervation of NOS expressing interneurons and cortical microvessels is present especially in the temporal cortex of $\mathrm{AD}$ patients. ${ }^{128,129}$ Collectively, these observations indicate that the basal forebrain cholinergic system has important effects on cortical blood flow regulation. Such changes in CBF are mediated by NO production through NOS interneurons provided by the nicotinic and muscarinic postsynaptic receptor system. Dysregulation of this system by chronic hypertension may be another important mechanism by which hypertension exerts its effects on cognitive processes.

\section{Hypertension, Genetics, and Cognition}

Contribution of genetic risk factors to disease phenotypes has been long established. Scientific advances during the last decade indicate that most such factors are not deterministic but instead act in concert with other environmental influences. A few such gene variants are now considered to have pleiotropic properties, allowing them to influence more than one pathologic process. Two such phenotypes are hypertension and neurocognitive loss. Although a complete discussion of the pleiotropic effects of such genetic variants influencing hypertension and cognitive loss is not possible in this review, the pleiotropic effects of variations at the ApoE and ACE loci are briefly discussed.

\section{Genetic variation at the apolipoprotein e locus and cerebral hypoperfusion-} Hypertension is causally linked to cerebral hypoperfusion. Evidence that a genetic variant potentiates cerebral hypoperfusion from a variety of causes is also known. The apolipoprotein E4 allele of the APOE gene (ApoE4) is the most consistent nondeterministic genetic risk factor for sporadic AD. Although several mechanisms are currently proposed to explain its effect on cognitive health, its relationship to cerebral hypoperfusion is increasingly noted, given the susceptibility of CBF to variation at the APOE locus. For example, ApoE4 associates with decrease in CBF velocity and enhances cerebrovascular amyloidogenesis in $\mathrm{AD} .{ }^{130} \mathrm{It}$ also associates with reduction in $\mathrm{CBF}$ in the parietal, temporal, 
and occipital areas in AD. However, whether ApoE4 directly potentiates the hypertensionrelated hypoperfusion resulting in decreased cerebral metabolism is yet to be established.

Genetic variation at the ACE locus and cognition-The vasoconstriction property of ACE is central to the pathogenesis of hypertension. Variations at the ACE gene locus have been associated with increased $\mathrm{AD}$ risk. Consistently, polymorphism in which there is deletion rather than insertion of a 287-base-pair sequence in intron 16 of the human ACE gene has been associated with increased serum ACE activity and therefore elevation of blood pressure. ${ }^{131}$ In humans homozygous for the D allele of the ACE gene, circulating ACE levels were found to be twice as high. However, studies on the relationship of ACE and $\mathrm{AD}$ have reported conflicting results. In a cohort of $350 \mathrm{AD}$ patients, ACE I allele frequency was $28 \%$, whereas another study found similar frequency in $\mathrm{AD}$ patients and Parkinson disease coexisting with AD pathology. ${ }^{132} \mathrm{~A}$ few other studies failed to confirm such an association, ${ }^{133,134}$ but instead observed an increase in ACE D allele prevalence and a reduced ACE I allele prevalence in older adults with age-associated memory loss. ${ }^{135}$ In a 4-year longitudinal study of 1168 subjects to investigate cognitive decline in older adults with different I/D genotypes, a strong association of homozygous ACE DD allele with lower performance on cognitive measures compared with subjects with ID and II alleles was reported. ${ }^{136}$ Although it seems premature to conclusively consider ACE gene polymorphism as a marker for $\mathrm{AD}$, the pleiotropic effect of $\mathrm{ACE}$ on hypertension, as well as on memory decline and/or AD, must be considered. Nonetheless, its effects on vasoconstriction, elevated blood pressure, and consequent cerebral hypoperfusion and cognitive loss are increasingly recognized.

\section{PREVENTION}

Preservation of neurocognitive function among those showing earliest signs and symptoms of $\mathrm{AD}$ ameliorates the physical, emotional, and economic burden associated with the disease. Unfortunately, this benefit and the national goals of Healthy People 2010 cannot be realized without an efficient AD prevention strategy. Although medical treatment after disease onset may reduce disease progression and mortality, eventually, increases in disease prevalence will substantially escalate total disease burden in the population. Whereas the current approach to symptomatic treatment of $\mathrm{AD}$ may not be cost-effective in populations with excessive rates of disease (such as African Americans), an intervention strategy with dual applicability for primary and secondary prevention is likely to be more beneficial.

Given the increases in the rates of hypertension and memory disorder with advancing age and the relationships of hyper- and hypotension with cognitive loss, available evidence indicates that aggressive control of elevated blood pressure to prevent dementia in the very old is unlikely to be an efficient public health goal. For hypertension to cofactor the initiation of neurodegeneration, more than 1 to 1.5 decades of uncontrolled hypertension may be required (see Fig. 5). These intervals vary depending on whether or not blood pressure is treated and controlled or uncontrolled. An additional 2 decades may be needed from the initiation of neurodegeneration to the phenotypic expression of meaningful cognitive loss. Cumulatively, from the onset of hypertension to the appearance of clinically significant cognitive loss, an interval of $\sim 35$ years may be required for hypertension to result in dementia. The actual duration is subject to the presence of other risk factors or lack of them. Therefore, for public health intervention to have a maximal impact, such efforts must be directed at preventing or aggressively controlling hypertension at the earliest possible stage, before the establishment of arterial stiffness and the need for higher pressure for optimal cerebral perfusion. Using JNC VII criteria, cognitively beneficial target blood pressure should be in the normal range $(<120 / 80 \mathrm{~mm} \mathrm{Hg}$ ) for persons aged less than 75 ; for persons aged 75 or older who have new-onset hypertension; and for diabetics irrespective of 
age. For persons aged 75 or older who have chronic hypertension, blood pressure in the prehypertensive range (120-139 $\mathrm{mm} \mathrm{Hg}$ ) is likely to be cognitively beneficial. Regardless of the duration and history of hypertension, cognitively beneficial target blood pressure for persons aged 80 or older should also remain in the prehypertensive range.

\section{LIMITATIONS OF THE CURRENT KNOWLEDGE}

Although most studies on the relationship of blood pressure to cognitive function reported beneficial effects of blood pressure in the normal range, a few found no relationship of elevated blood pressure with enhanced cognitive function. Others reported relationships ranging from a $\mathrm{J}$ - to a $\mathrm{U}$-shape. Because this is newly emerging evidence, most of these studies were population-based, often involving large numbers of subjects. Mostly, the studies varied in their inclusion and exclusion criteria and in their classification of hypertension, including the range of blood pressure that was considered normal. Because they are mostly nonprospective in nature, the investigators were constrained by the cognitive measure originally used in these studies. Given the multitude of neuropsychological measures to choose from, it is not surprising that many of these studies used different cognitive batteries to assess different cognitive domains. Because the exact cognitive domain that is mostly affected by hypertension is yet to be ascertained, it not surprising that the results from these studies were varied.

It should be emphasized that cross-sectional studies are limited in their ability to establish directionality, because blood pressure and cognitive outcomes are assessed simultaneously. Because prospective studies have the advantage of time, measuring exposure to blood pressure and cognitive outcomes later on in life, it is rational to expect that they would be advantageous in assessing the association between blood pressure and cognitive reserve. Although most studies have demonstrated an association between elevated blood pressure and cognitive loss, there remains inconsistency in the findings. Possible explanations for this inconsistency include differences in sample size, duration of follow-up, and inclusionexclusion criteria; the extent to which subjects' blood pressures were controlled; duration of medication use; and the type of psychological measures and cognitive domains that were assessed. Whether or not important covariants such as age, gender, ethnicity, education, aerobic fitness, body mass index, type 2 diabetes, and genetic variations at the APOE locus were considered may have contributed to such inconsistencies.

For the available randomized controlled trials, cognition was not the primary endpoint for most, which calls into question the design of such studies. It appears that certain classes or particular medications are more cognitively beneficial than others. Classes of medication used in most of the available randomized studies varied, ranging from diuretics, $\beta$-blockers, non-DHP- and DHP-CCBs, ACE inhibitors, and ARBs. In spite of the evidence that showed that the duration of treatment is important to the cognitively beneficial treatment effects, often, treatment duration was either not considered or not reported in most of these studies. Finally, it appears that long duration of hypertension may be required for its harmful effects on cognitive outcomes to manifest. Because cognitive outcomes were not the primary endpoint for most of these studies, they were unlikely to be of sufficient duration or of adequate power, or they used alternative approaches such as an enriched sample to compensate for duration and power to detect differences.

Because the NHANES III data are some of the most important data available on the national estimates of the prevalence of hypertension and its relationship to cognitive function, their limitations are worth special consideration. The NHANES III is advantaged in that it permits age-stratified analysis and adjustment for multiple confounders and therefore is a more robust assessment of the relationship of blood pressure and PPR to cognitive measure. 
Several unavoidable limitations of the NHANES data include possible bias from survey nonresponse and from missing values for some variables, and bias from self-reported history of hypertension as in other cross-sectional studies. Fortunately, the conclusions by Obisesan and colleagues ${ }^{17}$ are not based on self-reported hypertension but rather on actual blood pressure measurements.

\section{SUMMARY}

Cumulative evidence implicates hypertension in the pathogenesis of AD. Although it may not presently be possible to completely discern the effects of treatment and control of hypertension itself from that of the medication used to achieve such treatment goals, efforts directed at the treatment and control of hypertension have significant public health impact.

Public health goals for optimal blood pressure should probably be age-specific. Because optimal blood pressure for optimal cognitive performance is yet to be clearly established and the undesirable effect of excessive reduction in blood pressure is not fully understood, the following recommendations are made using JNC VII criteria: target blood pressure beneficial to cognition should be in the normal range $(<120 / 80 \mathrm{~mm} \mathrm{Hg})$ for persons 75 years or younger, for persons aged 75 or older having new-onset hypertension, and for persons with diabetes irrespective of age. For persons aged 75 or older who have chronic hypertension, blood pressure in the prehypertensive range $(120-139 \mathrm{~mm} \mathrm{Hg})$ is likely to be cognitively beneficial. Regardless of duration and history of hypertension, cognitively beneficial target blood pressure for persons aged 80 or older should also remain in the prehypertensive range.

If indeed hypertension is a risk factor for $\mathrm{AD}$ or shares the same pathophysiology, it is logical to expect that measures directed at blood pressure control will enhance cognitive reserve. This is an important public health goal.

\section{Acknowledgments}

Supported by grant numbers: AG00980 (TOO) from the National Institute of Health, and RO1 AG02213 (RCG) also from the National Institute of Health.

\section{References}

1. Johnson P. Fiscal implications of population ageing. Philos Trans R Soc Lond B Biol Sci. 1997; 352:1895-903. [PubMed: 9460075]

2. Serow WJ. Economic and fiscal implications of aging for subnational American governments. J Aging Soc Policy. 2001; 12:47-63. [PubMed: 11799914]

3. Covinsky KE, Eng C, Lui LY, et al. The last 2 years of life: functional trajectories of frail older people. J Am Geriatr Soc. 2003; 51:492-8. [PubMed: 12657068]

4. Hamel E, Nicolakakis N, Aboulkassim T, et al. Oxidative stress and cerebrovascular dysfunction in mouse models of Alzheimer's disease. Exp Physiol. 2008; 93:116-20. [PubMed: 17911359]

5. Breteler MM, van den Ouweland FA, Grobbee DE, et al. A community-based study of dementia: the Rotterdam Elderly Study. Neuroepidemiology. 1992; 11(Suppl 1):23-8. [PubMed: 1603244]

6. Hachinski V, Munoz DG. Cerebrovascular pathology in Alzheimer's disease: cause, effect or epiphenomenon? Ann N Y Acad Sci. 1997; 826:1-6. [PubMed: 9329676]

7. White L, Petrovitch H, Hardman J, et al. Cerebrovascular pathology and dementia in autopsied Honolulu-Asia aging study participants. Ann N Y Acad Sci. 2002; 977:9-23. [PubMed: 12480729]

8. Van Nostrand WE, Davis-Salinas J, Saporito-Irwin SM. Amyloid beta-protein induces the cerebrovascular cellular pathology of Alzheimer's disease and related disorders. Ann N Y Acad Sci. 1996; 777:297-302. [PubMed: 8624102] 
9. Tzourio C. Hypertension, cognitive decline, and dementia: an epidemiological perspective. Dialogues Clin Neurosci. 2007; 9:61-70. [PubMed: 17506226]

10. Peila R, White LR, Masaki K, et al. Reducing the risk of dementia: efficacy of long-term treatment of hypertension. Stroke. 2006; 37:1165-70. [PubMed: 16601212]

11. Kivipelto M, Helkala EL, Hanninen T, et al. Midlife vascular risk factors and late-life mild cognitive impairment: a population-based study. Neurology. 2001; 56:1683-9. [PubMed: 11425934]

12. Launer LJ, Ross GW, Petrovitch H, et al. Midlife blood pressure and dementia: the Honolulu-Asia aging study. Neurobiol Aging. 2000; 21:49-55. [PubMed: 10794848]

13. Skoog I, Lernfelt B, Landahl S, et al. 15-year longitudinal study of blood pressure and dementia. Lancet. 1996; 347:1141-5. [PubMed: 8609748]

14. Frishman WH. Are antihypertensive agents protective against dementia? A review of clinical and preclinical data. Heart Dis. 2002; 4:380-6. [PubMed: 12441015]

15. Manolio TA, Olson J, Longstreth WT. Hypertension and cognitive function: pathophysiologic effects of hypertension on the brain. Curr Hypertens Rep. 2003; 5:255-61. [PubMed: 12724059]

16. Korf ES, White LR, Scheltens P, et al. Midlife blood pressure and the risk of hippocampal atrophy: the Honolulu Asia aging study. Hypertension. 2004; 44:29-34. [PubMed: 15159381]

17. Obisesan TO, Obisesan OA, Martins S, et al. High blood pressure, hypertension, and high pulse pressure are associated with poorer cognitive function in persons aged 60 and older: the Third National Health and Nutrition Examination Survey. J Am Geriatr Soc. 2008; 56:501-9. [PubMed: 18179496]

18. Forette F, Seux ML, Staessen JA, et al. Prevention of dementia in randomised double-blind placebo-controlled Systolic Hypertension in Europe (Syst-Eur) trial. Lancet. 1998; 352:1347-51. [PubMed: 9802273]

19. Forette F, Seux ML, Staessen JA, et al. The prevention of dementia with antihypertensive treatment: new evidence from the Systolic Hypertension in Europe (Syst-Eur) study. Arch Intern Med. 2002; 162:2046-52. [PubMed: 12374512]

20. Tzourio C, Anderson C, Chapman N, et al. Effects of blood pressure lowering with perindopril and indapamide therapy on dementia and cognitive decline in patients with cerebrovascular disease. Arch Intern Med. 2003; 163:1069-75. [PubMed: 12742805]

21. Bosch J, Yusuf S, Pogue J, et al. Use of ramipril in preventing stroke: double blind randomised trial. BMJ. 2002; 324:699-702. [PubMed: 11909785]

22. Peters R, Beckett N, Forette F, et al. Incident dementia and blood pressure lowering in the Hypertension in the Very Elderly Trial cognitive function assessment (HYVET-COG): a doubleblind, placebo controlled trial. Lancet Neurol. 2008; 7:683-9. [PubMed: 18614402]

23. Kahonen-Vare M, Brunni-Hakala S, Lindroos M, et al. Left ventricular hypertrophy and blood pressure as predictors of cognitive decline in old age. Aging Clin Exp Res. 2004; 16:147-52. [PubMed: 15195990]

24. Kuo HK, Sorond F, Iloputaife I, et al. Effect of blood pressure on cognitive functions in elderly persons. J Gerontol A Biol Sci Med Sci. 2004; 59:1191-4. [PubMed: 15602074]

25. Waldstein SR, Brown JR, Maier KJ, et al. Diagnosis of hypertension and high blood pressure levels negatively affect cognitive function in older adults. Ann Behav Med. 2005; 29:174-80. [PubMed: 15946111]

26. Waldstein SR, Katzel LI. Stress-induced blood pressure reactivity and cognitive function. Neurology. 2005; 64:1746-9. [PubMed: 15911802]

27. The sixth report of the Joint National Committee on prevention, detection, evaluation, and treatment of high blood pressure. Arch Intern Med. 1997; 157:2413-46. [PubMed: 9385294]

28. St Clair D, Whalley LJ. Hypertension, multi-infarct dementia and Alzheimer's disease. Br J Psychiatry. 1983; 143:274-6. [PubMed: 6626840]

29. Sadowski M, Pankiewicz J, Scholtzova H, et al. Links between the pathology of Alzheimer's disease and vascular dementia. Neurochem Res. 2004; 29:1257-66. [PubMed: 15176482]

30. Reitz C, Patel B, Tang MX, et al. Relation between vascular risk factors and neuropsychological test performance among elderly persons with Alzheimer's disease. J Neurol Sci. 2007; 257:194201. [PubMed: 17328914] 
31. Petrovitch H, Ross GW, Steinhorn SC, et al. AD lesions and infarcts in demented and nondemented Japanese-American men. Ann Neurol. 2005; 57:98-103. [PubMed: 15562458]

32. Petrovitch H, White LR, Izmirilian G, et al. Midlife blood pressure and neuritic plaques, neurofibrillary tangles, and brain weight at death: the HAAS. Honolulu-Asia aging study. Neurobiol Aging. 2000; 21:57-62. [PubMed: 10794849]

33. Cacciatore F, Abete P, Ferrara N, et al. The role of blood pressure in cognitive impairment in an elderly population. Osservatorio Geriatrico Campano Group. J Hypertens. 1997; 15:135-42. [PubMed: 9469788]

34. Richards SS, Emsley CL, Roberts J, et al. The association between vascular risk factor-mediating medications and cognition and dementia diagnosis in a community-based sample of AfricanAmericans. J Am Geriatr Soc. 2000; 48:1035-41. [PubMed: 10983901]

35. Hajjar I, Catoe H, Sixta S, et al. Cross-sectional and longitudinal association between antihypertensive medications and cognitive impairment in an elderly population. J Gerontol A Biol Sci Med Sci. 2005; 60:67-73. [PubMed: 15741285]

36. Lindsay J, Laurin D, Verreault R, et al. Risk factors for Alzheimer's disease: a prospective analysis from the Canadian study of health and aging. Am J Epidemiol. 2002; 156:445-53. [PubMed: 12196314]

37. Morris MS, Jacques PF, Rosenberg IH, et al. Hyperhomocysteinemia associated with poor recall in the third National Health and Nutrition Examination Survey. Am J Clin Nutr. 2001; 73:927-33. [PubMed: 11333847]

38. Duron E, Hanon O. Vascular risk factors, cognitive decline, and dementia. Vasc Health Risk Manag. 2008; 4:363-81. [PubMed: 18561512]

39. Bellew KM, Pigeon JG, Stang PE, et al. Hypertension and the rate of cognitive decline in patients with dementia of the Alzheimer type. Alzheimer Dis Assoc Disord. 2004; 18:208-13. [PubMed: 15592132]

40. Hanon O, Haulon S, Lenoir H, et al. Relationship between arterial stiffness and cognitive function in elderly subjects with complaints of memory loss. Stroke. 2005; 36:2193-7. [PubMed: 16151027]

41. Verghese J, Lipton RB, Hall CB, et al. Low blood pressure and the risk of dementia in very old individuals. Neurology. 2003; 61:1667-72. [PubMed: 14694027]

42. Sparks DL, Scheff SW, Liu H, et al. Increased incidence of neurofibrillary tangles (NFT) in nondemented individuals with hypertension. J Neurol Sci. 1995; 131:162-9. [PubMed: 7595642]

43. Guo Z, Viitanen M, Winblad B, et al. Low blood pressure and incidence of dementia in a very old sample: dependent on initial cognition. J Am Geriatr Soc. 1999; 47:723-6. [PubMed: 10366174]

44. Tzourio C, Dufouil C, Ducimetiere P, et al. Cognitive decline in individuals with high blood pressure: a longitudinal study in the elderly. EVA Study Group. Epidemiology of Vascular Aging. Neurology. 1999; 53:1948-52. [PubMed: 10599763]

45. Murray MD, Lane KA, Gao S, et al. Preservation of cognitive function with anti-hypertensive medications: a longitudinal analysis of a community-based sample of African Americans. Arch Intern Med. 2002; 162:2090-6. [PubMed: 12374517]

46. Yasar S, Corrada M, Brookmeyer R, et al. Calcium channel blockers and risk of AD: the Baltimore longitudinal study of aging. Neurobiol Aging. 2005; 26:157-63. [PubMed: 15582745]

47. Khachaturian AS, Zandi PP, Lyketsos CG, et al. Antihypertensive medication use and incident Alzheimer disease: the Cache County Study. Arch Neurol. 2006; 63:686-92. [PubMed: 16533956]

48. Salas M, In't Veld BA, van der Linden PD, et al. Impaired cognitive function and compliance with antihypertensive drugs in elderly: the Rotterdam Study. Clin Pharmacol Ther. 2001; 70:561-6. [PubMed: 11753273]

49. Hanon O, Pequignot R, Seux ML, et al. Relationship between antihypertensive drug therapy and cognitive function in elderly hypertensive patients with memory complaints. J Hypertens. 2006; 24:2101-7. [PubMed: 16957572]

50. Starr JM, Whalley LJ, Deary IJ. The effects of antihypertensive treatment on cognitive function: results from the HOPE study. J Am Geriatr Soc. 1996; 44:411-5. [PubMed: 8636587] 
51. Feigin V, Ratnasabapathy Y, Anderson C. Does blood pressure lowering treatment prevent dementia or cognitive decline in patients with cardiovascular and cerebrovascular disease? $\mathrm{J}$ Neurol Sci. 2005; 229-230:151-5.

52. Birkenhager WH, Staessen JA. Progress in cardiovascular diseases: cognitive function in essential hypertension. Prog Cardiovasc Dis. 2006; 49:1-10. [PubMed: 16867845]

53. Prince MJ, Bird AS, Blizard RA, et al. Is the cognitive function of older patients affected by antihypertensive treatment? Results from 54 months of the Medical Research Council's trial of hypertension in older adults. BMJ. 1996; 312:801-5. [PubMed: 8608285]

54. Lithell H, Hansson L, Skoog I, et al. The Study on Cognition and Prognosis in the Elderly (SCOPE): principal results of a randomized double-blind intervention trial. J Hypertens. 2003; 21:875-86. [PubMed: 12714861]

55. McGuinness B, Todd S, Passmore P, et al. The effects of blood pressure lowering on development of cognitive impairment and dementia in patients without apparent prior cerebrovascular disease. Cochrane Database Syst Rev. 2006; 2:CD004034. [PubMed: 16625595]

56. Gard PR. Angiotensin as a target for the treatment of Alzheimer's disease, anxiety and depression. Expert Opin Ther Targets. 2004; 8:7-14. [PubMed: 14996614]

57. Heckbert SR, Longstreth WT Jr, Psaty BM, et al. The association of antihypertensive agents with MRI white matter findings and with modified mini-mental state examination in older adults. J Am Geriatr Soc. 1997; 45:1423-33. [PubMed: 9400550]

58. Maxwell CJ, Hogan DB, Ebly EM. Calcium-channel blockers and cognitive function in elderly people: results from the Canadian study of health and aging. CMAJ. 1999; 161:501-6. [PubMed: 10497605]

59. Morris MC, Scherr PA, Hebert LE, et al. Association of incident Alzheimer disease and blood pressure measured from 13 years before to 2 years after diagnosis in a large community study. Arch Neurol. 2001; 58:1640-6. [PubMed: 11594923]

60. Qiu C, von Strauss E, Fastbom J, et al. Low blood pressure and risk of dementia in the Kungsholmen project: a 6-year follow-up study. Arch Neurol. 2003; 60:223-8. [PubMed: 12580707]

61. Qiu C, von Strauss E, Winblad B, et al. Decline in blood pressure over time and risk of dementia: a longitudinal study from the Kungsholmen project. Stroke. 2004; 35:1810-5. [PubMed: 15232128]

62. Ruitenberg A, Skoog I, Ott A, et al. Blood pressure and risk of dementia: results from the Rotterdam study and the Gothenburg H-70 Study. Dement Geriatr Cogn Disord. 2001; 12:33-9. [PubMed: 11125239]

63. Lee AY, Jeong SH, Choi BH, et al. Pulse pressure correlates with leukoaraiosis in Alzheimer disease. Arch Gerontol Geriatr. 2006; 42:157-66. [PubMed: 16139378]

64. Waldstein SR, Giggey PP, Thayer JF, et al. Nonlinear relations of blood pressure to cognitive function: the Baltimore Longitudinal Study of Aging. Hypertension. 2005; 45:374-9. [PubMed: 15699446]

65. Qiu C, Winblad B, Viitanen M, et al. Pulse pressure and risk of Alzheimer disease in persons aged 75 years and older: a community-based, longitudinal study. Stroke. 2003; 34:594-9. [PubMed: 12624277]

66. Morris MC, Scherr PA, Hebert LE, et al. Association between blood pressure and cognitive function in a biracial community population of older persons. Neuroepidemiology. 2002; 21 :12330. [PubMed: 12006775]

67. Perlmutter LS, Barron E, Saperia D, et al. Association between vascular basement membrane components and the lesions of Alzheimer's disease. J Neurosci Res. 1991; 30:673-81. [PubMed: 1787541]

68. Hardy JA, Mann DM, Wester P, et al. An integrative hypothesis concerning the pathogenesis and progression of Alzheimer's disease. Neurobiol Aging. 1986; 7:489-502. [PubMed: 2882432]

69. Lukiw WJ, Bazan NG. Cyclooxygenase 2 RNA message abundance, stability, and hypervariability in sporadic Alzheimer neocortex. J Neurosci Res. 1997; 50:937-45. [PubMed: 9452008]

70. Perkins DJ, Kniss DA. Tumor necrosis factor-alpha promotes sustained cyclooxygenase-2 expression: attenuation by dexamethasone and NSAIDs. Prostaglandins. 1997; 54:727-43. [PubMed: 9440135] 
71. Modzelewski R, de la Rue T, Janvresse E, et al. Development and validation of the random walk algorithm: application to the classification of diffuse heterogeneity in brain SPECT perfusion images. J Comput Assist Tomogr. 2008; 32:651-9. [PubMed: 18664857]

72. Waragai M, Mizumura S, Yamada T, et al. Differentiation of early-stage Alzheimer's disease from other types of dementia using brain perfusion single photon emission computed tomography with easy Z-score imaging system analysis. Dement Geriatr Cogn Disord. 2008; 26:547-55. [PubMed: 19066428]

73. Kobayashi S, Tateno M, Utsumi K, et al. Quantitative analysis of brain perfusion SPECT in Alzheimer's disease using a fully automated regional cerebral blood flow quantification software, 3DSRT. J Neurol Sci. 2008; 264:27-33. [PubMed: 17764699]

74. Tsolaki M, Sakka V, Gerasimou G, et al. Correlation of rCBF (SPECT), CSF tau, and cognitive function in patients with dementia of the Alzheimer's type, other types of dementia, and control subjects. Am J Alzheimers Dis Other Demen. 2001; 16:21-31. [PubMed: 11416945]

75. Ueda H, Kitabayashi Y, Narumoto J, et al. Relationship between clock drawing test performance and regional cerebral blood flow in Alzheimer's disease: a single photon emission computed tomography study. Psychiatry Clin Neurosci. 2002; 56(1):25-9. [PubMed: 11929568]

76. Jagust WJ, Eberling JL, Reed BR, et al. Clinical studies of cerebral blood flow in Alzheimer's disease. Ann N Y Acad Sci. 1997; 826:254-62. [PubMed: 9329697]

77. Ushijima Y, Okuyama C, Mori S, et al. Relationship between cognitive function and regional cerebral blood flow in Alzheimer's disease. Nucl Med Commun. 2002; 23:779-84. [PubMed: 12124484]

78. Nagahama Y, Nabatame H, Okina T, et al. Cerebral correlates of the progression rate of the cognitive decline in probable Alzheimer's disease. Eur Neurol. 2003; 50:1-9. [PubMed: 12824705]

79. Bots ML, Witteman JC, Hofman A, et al. Low diastolic blood pressure and atherosclerosis in elderly subjects. The Rotterdam study. Arch Intern Med. 1996; 156:843-8. [PubMed: 8774202]

80. Liao D, Arnett DK, Tyroler HA, et al. Arterial stiffness and the development of hypertension. The ARIC study. Hypertension. 1999; 34:201-6. [PubMed: 10454441]

81. Chambless LE, Folsom AR, Davis V, et al. Risk factors for progression of common carotid atherosclerosis: the Atherosclerosis Risk in Communities Study, 1987-1998. Am J Epidemiol. 2002; 155:38-47. [PubMed: 11772783]

82. Farkas E, Luiten PG. Cerebral microvascular pathology in aging and Alzheimer's disease. Prog Neurobiol. 2001; 64:575-611. [PubMed: 11311463]

83. Iadecola C. Neurovascular regulation in the normal brain and in Alzheimer's disease. Nat Rev Neurosci. 2004; 5:347-60. [PubMed: 15100718]

84. Iadecola C, Zhang F, Niwa K, et al. SOD1 rescues cerebral endothelial dysfunction in mice overexpressing amyloid precursor protein. Nat Neurosci. 1999; 2:157-61. [PubMed: 10195200]

85. Niwa K, Porter VA, Kazama K, et al. A beta-peptides enhance vasoconstriction in cerebral circulation. Am J Physiol Heart Circ Physiol. 2001; 281:H2417-24. [PubMed: 11709407]

86. Crawford F, Suo Z, Fang C, et al. Characteristics of the in vitro vasoactivity of beta-amyloid peptides. Exp Neurol. 1998; 150:159-68. [PubMed: 9514824]

87. Zlokovic BV, Deane R, Sallstrom J, et al. Neurovascular pathways and Alzheimer amyloid betapeptide. Brain Pathol. 2005; 15:78-83. [PubMed: 15779240]

88. Attwell D, Iadecola C. The neural basis of functional brain imaging signals. Trends Neurosci. 2002; 25:621-5. [PubMed: 12446129]

89. Ide K, Secher NH. Cerebral blood flow and metabolism during exercise. Prog Neurobiol. 2000; 61:397-414. [PubMed: 10727781]

90. Wolf RL, Alsop DC, Levy-Reis I, et al. Detection of mesial temporal lobe hypoperfusion in patients with temporal lobe epilepsy by use of arterial spin labeled perfusion MR imaging. AJNR Am J Neuroradiol. 2001; 22:1334-41. [PubMed: 11498422]

91. Heistad DD. Summary of symposium on cerebral blood flow: effect of nerves and neurotransmitters. Cardiovascular Center, University of Iowa, Iowa City, Iowa, June 16-18, 1981. J Cereb Blood Flow Metab. 1981; 1:447-50. [PubMed: 6120176] 
92. Baumbach GL, Heistad DD. Regional, segmental, and temporal heterogeneity of cerebral vascular autoregulation. Ann Biomed Eng. 1985; 13:303-10. [PubMed: 3898928]

93. Daley ML, Pourcyrous M, Timmons SD, et al. Assessment of cerebrovascular autoregulation: changes of highest modal frequency of cerebrovascular pressure transmission with cerebral perfusion pressure. Stroke. 2004; 35:1952-6. [PubMed: 15205491]

94. de la Torre JC. Critical threshold cerebral hypoperfusion causes Alzheimer's disease? Acta Neuropathol. 1999; 98:1-8. [PubMed: 10412794]

95. de la Torre JC. Impaired cerebromicrovascular perfusion. Summary of evidence in support of its causality in Alzheimer's disease. Ann N Y Acad Sci. 2000; 924:136-52. [PubMed: 11193790]

96. de la Torre JC. Critically attained threshold of cerebral hypoperfusion: the CATCH hypothesis of Alzheimer's pathogenesis. Neurobiol Aging. 2000; 21:331-42. [PubMed: 10867218]

97. de la Torre JC. Cerebral hypoperfusion, capillary degeneration, and development of Alzheimer disease. Alzheimer Dis Assoc Disord. 2000; 14(Suppl 1):S72-81. [PubMed: 10850734]

98. de la Torre JC. Alzheimer disease as a vascular disorder: nosological evidence. Stroke. 2002; 33:1152-62. [PubMed: 11935076]

99. Prunell GF, Mathiesen T, Svendgaard NA. Experimental subarachnoid hemorrhage: cerebral blood flow and brain metabolism during the acute phase in three different models in the rat. Neurosurgery. 2004; 54:426-36. [discussion: 36-7]. [PubMed: 14744290]

100. Warkentin S, Ohlsson M, Wollmer P, et al. Regional cerebral blood flow in Alzheimer's disease: classification and analysis of heterogeneity. Dement Geriatr Cogn Disord. 2004; 17:207-14. [PubMed: 14739546]

101. Johnson KA, Jones K, Holman BL, et al. Preclinical prediction of Alzheimer's disease using SPECT. Neurology. 1998; 50:1563-71. [PubMed: 9633695]

102. Matsuda H. Cerebral blood flow and metabolic abnormalities in Alzheimer's disease. Ann Nucl Med. 2001; 15:85-92. [PubMed: 11448080]

103. Reckelhoff JF, Romero JC. Role of oxidative stress in angiotensin-induced hypertension. Am J Physiol Regul Integr Comp Physiol. 2003; 284:R893-912. [PubMed: 12626356]

104. Amouyel P, Richard F, Berr C, et al. The renin angiotensin system and Alzheimer's disease. Ann N Y Acad Sci. 2000; 903:437-41. [PubMed: 10818534]

105. McKinley MJ, Albiston AL, Allen AM, et al. The brain renin-angiotensin system: location and physiological roles. Int J Biochem Cell Biol. 2003; 35:901-18. [PubMed: 12676175]

106. Gard PR. The role of angiotensin II in cognition and behaviour. Eur J Pharmacol. 2002; 438:114. [PubMed: 11906704]

107. Sharma P. Meta-analysis of the ACE gene in ischaemic stroke. J Neurol Neurosurg Psychiatr. 1998; 64:227-30. [PubMed: 9489536]

108. Phillips MI, de Oliveira EM. Brain renin angiotensin in disease. J Mol Med. 2008; 86:715-22. [PubMed: 18385968]

109. Markus HS, Barley J, Lunt R, et al. Angiotensin-converting enzyme gene deletion polymorphism. A new risk factor for lacunar stroke but not carotid atheroma. Stroke. 1995; 26:1329-33. [PubMed: 7631331]

110. von Bohlen und Halbach O, Albrecht D. The CNS renin-angiotensin system. Cell Tissue Res. 2006; 326:599-616. [PubMed: 16555051]

111. Raghavendra V, Chopra K, Kulkarni SK. Comparative studies on the memory-enhancing actions of captopril and losartan in mice using inhibitory shock avoidance paradigm. Neuropeptides. 2001; 35:65-9. [PubMed: 11346312]

112. Bonini JS, Bevilaqua LR, Zinn CG, et al. Angiotensin II disrupts inhibitory avoidance memory retrieval. Horm Behav. 2006; 50:308-13. [PubMed: 16697382]

113. de Souza FA, Sanchis-Segura C, Fukada SY, et al. Intracerebroventricular effects of angiotensin II on a step-through passive avoidance task in rats. Neurobiol Learn Mem. 2004; 81:100-3. [PubMed: 14670364]

114. Hu J, Igarashi A, Kamata M, et al. Angiotensin-converting enzyme degrades Alzheimer amyloid beta-peptide (A beta); retards A beta aggregation, deposition, fibril formation; and inhibits cytotoxicity. J Biol Chem. 2001; 276:47863-8. [PubMed: 11604391] 
115. Denny JB, Polan-Curtain J, Wayner MJ, et al. Angiotensin II blocks hippocampal long-term potentiation. Brain Res. 1991; 567:321-4. [PubMed: 1817736]

116. Baranowska D, Braszko JJ, Wisniewski K. Effect of angiotensin II and vasopressin on acquisition and extinction of conditioned avoidance in rats. Psychopharmacology (Berl). 1983; 81:247-51. [PubMed: 6417715]

117. Selley ML. Increased concentrations of homocysteine and asymmetric dimethylarginine and decreased concentrations of nitric oxide in the plasma of patients with Alzheimer's disease. Neurobiol Aging. 2003; 24:903-7. [PubMed: 12928048]

118. McCarron RM, Chen Y, Tomori T, et al. Endothelial-mediated regulation of cerebral microcirculation. J Physiol Pharmacol. 2006; 57(Suppl 11):133-44. [PubMed: 17244945]

119. Maxwell AJ. Mechanisms of dysfunction of the nitric oxide pathway in vascular diseases. Nitric Oxide. 2002; 6:101-24. [PubMed: 11890735]

120. Cooke JP, Dzau VJ. Nitric oxide synthase: role in the genesis of vascular disease. Annu Rev Med. 1997; 48:489-509. [PubMed: 9046979]

121. Chen ZY, Su YL, Lau CW, et al. Endothelium-dependent contraction and direct relaxation induced by baicalein in rat mesenteric artery. Eur J Pharmacol. 1999; 374:41-7. [PubMed: 10422639]

122. Rodrigo J, Fernandez AP, Alonso D, et al. Nitric oxide in the rat cerebellum after hypoxia/ ischemia. Cerebellum. 2004; 3:194-203. [PubMed: 15686097]

123. Fernandez-Vizarra P, Fernandez AP, Castro-Blanco S, et al. Expression of nitric oxide system in clinically evaluated cases of Alzheimer's disease. Neurobiol Dis. 2004; 15:287-305. [PubMed: 15006699]

124. Rodrigo J, Fernandez-Vizarra P, Castro-Blanco S, et al. Nitric oxide in the cerebral cortex of amyloid-precursor protein (SW) Tg2576 transgenic mice. Neuroscience. 2004; 128:73-89. [PubMed: 15450355]

125. Lee TJ. Nitric oxide and the cerebral vascular function. J Biomed Sci. 2000; 7:16-26. [PubMed: 10644885]

126. Nakajima K, Uchida S, Suzuki A, et al. The effect of walking on regional blood flow and acetylcholine in the hippocampus in conscious rats. Auton Neurosci. 2003; 103:83-92. [PubMed: 12531401]

127. Moro V, Kacem K, Springhetti V, et al. Microvessels isolated from brain: localization of muscarinic sites by radioligand binding and immunofluorescent techniques. J Cereb Blood Flow Metab. 1995; 15:1082-92. [PubMed: 7593341]

128. Hamel E. Cholinergic modulation of the cortical microvascular bed. Prog Brain Res. 2004; 145:171-8. [PubMed: 14650915]

129. Tong XK, Hamel E. Regional cholinergic denervation of cortical microvessels and nitric oxide synthase-containing neurons in Alzheimer's disease. Neuroscience. 1999; 92:163-75. [PubMed: 10392839]

130. Martel CL, Mackic JB, Matsubara E, et al. Isoform-specific effects of apolipoproteins E2, E3, and E4 on cerebral capillary sequestration and blood-brain barrier transport of circulating Alzheimer's amyloid beta. J Neurochem. 1997; 69:1995-2004. [PubMed: 9349544]

131. Rigat B, Hubert C, Alhenc-Gelas F, et al. An insertion/deletion polymorphism in the angiotensin I-converting enzyme gene accounting for half the variance of serum enzyme levels. J Clin Invest. 1990; 86:1343-6. [PubMed: 1976655]

132. Alvarez R, Alvarez V, Lahoz CH, et al. Angiotensin converting enzyme and endothelial nitric oxide synthase DNA polymorphisms and late onset Alzheimer's disease. J Neurol Neurosurg Psychiatr. 1999; 67:733-6. [PubMed: 10567488]

133. Monastero R, Caldarella R, Mannino M, et al. Lack of association between angiotensin converting enzyme polymorphism and sporadic Alzheimer's disease. Neurosci Lett. 2002; 335:147-9. [PubMed: 12459519]

134. Lendon CL, Thaker U, Harris JM, et al. The angiotensin 1-converting enzyme insertion (I)/ deletion (D) polymorphism does not influence the extent of amyloid or tau pathology in patients with sporadic Alzheimer's disease. Neurosci Lett. 2002; 328:314-8. [PubMed: 12147333] 
135. Bartres-Faz D, Junque C, Clemente IC, et al. Angiotensin I converting enzyme polymorphism in humans with age-associated memory impairment: relationship with cognitive performance. Neurosci Lett. 2000; 290:177-80. [PubMed: 10963892]

136. Richard F, Berr C, Amant C, et al. Effect of the angiotensin I-converting enzyme I/D polymorphism on cognitive decline. The EVA Study Group. Neurobiol Aging. 2000; 21:75-80. [PubMed: 10794851] 


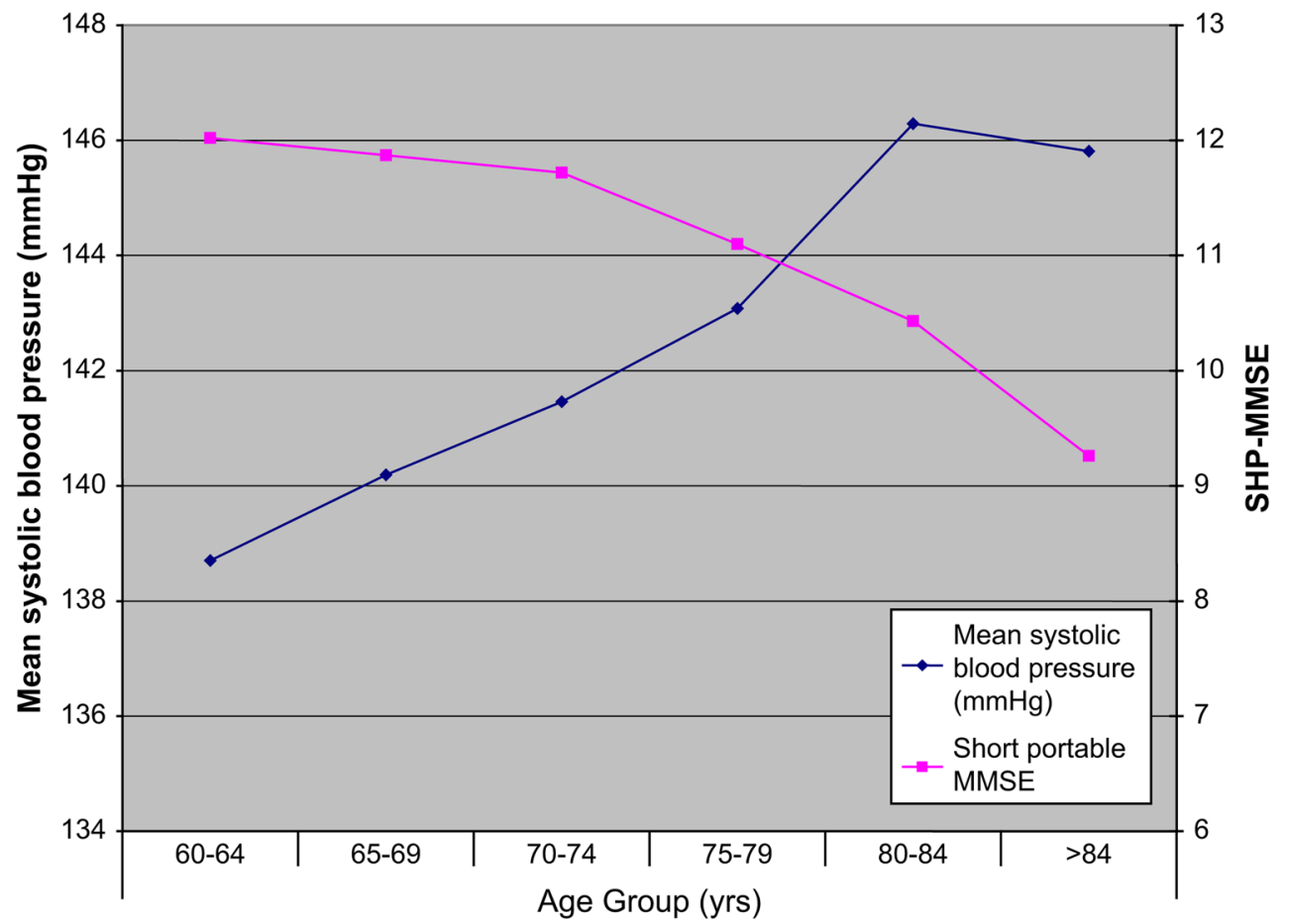

Fig.1.

Mean SBP and short portable MMSE score by increasing age groups. 


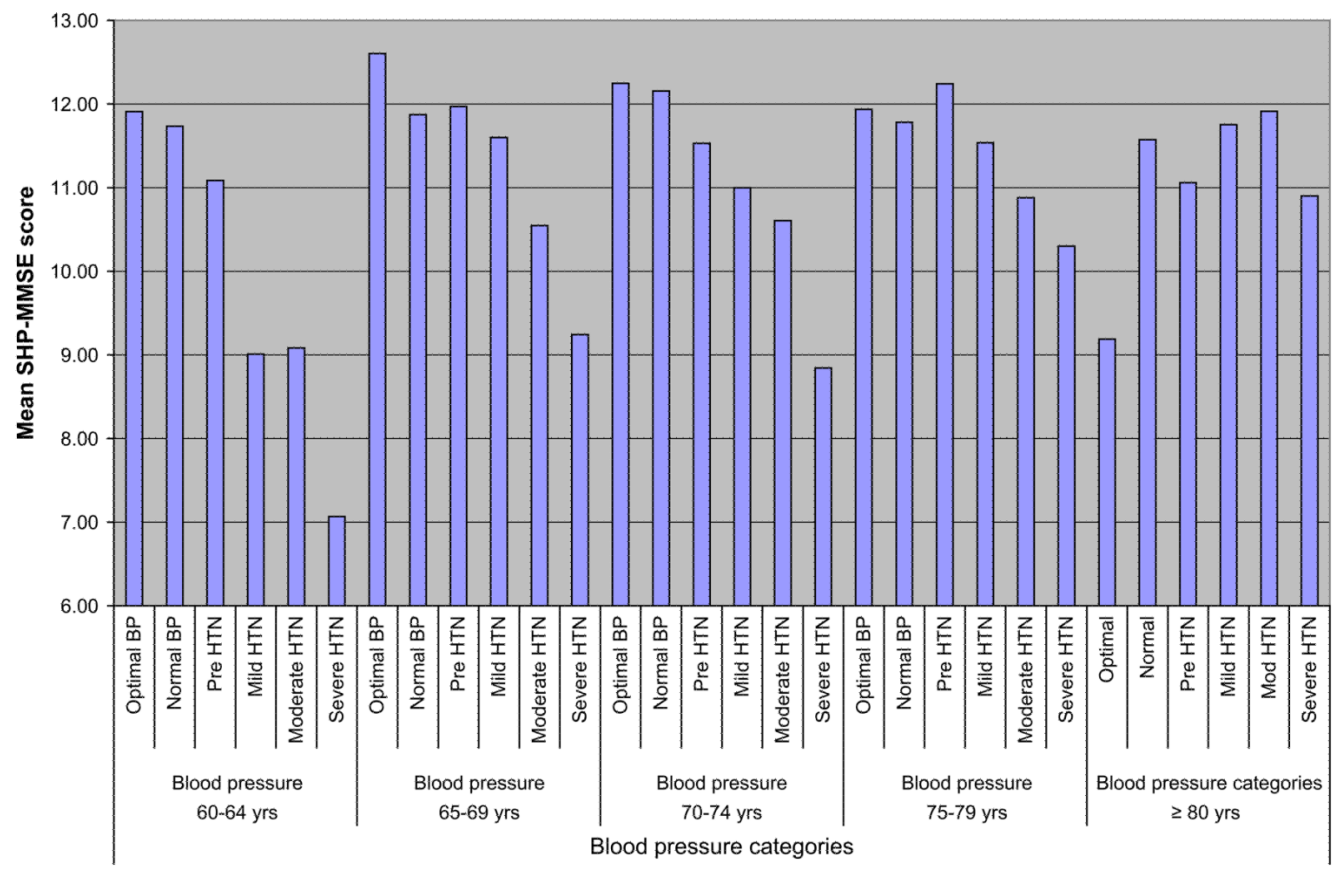

Fig. 2.

Short portable MMSE score by JNC VI blood pressure categories in different age groups. Note: sp-MMSE indicates Short Portable Mini-Mental State Examination 


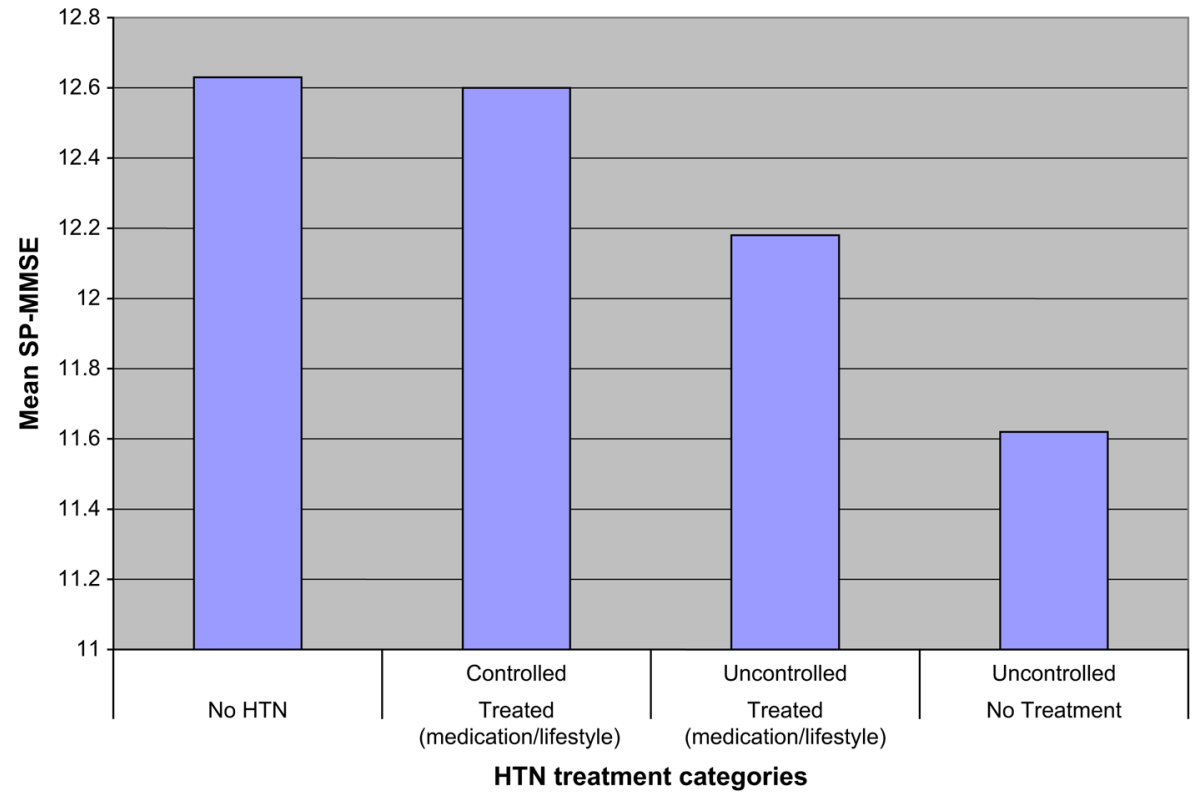

Fig. 3.

Short portable MMSE score by treatment categories.

Note: Mean Short Portable Mini-Mental State Examination (sp-MMSE) score adjusted for age, gender, ethnicity, education, income, and pulse pressure. 


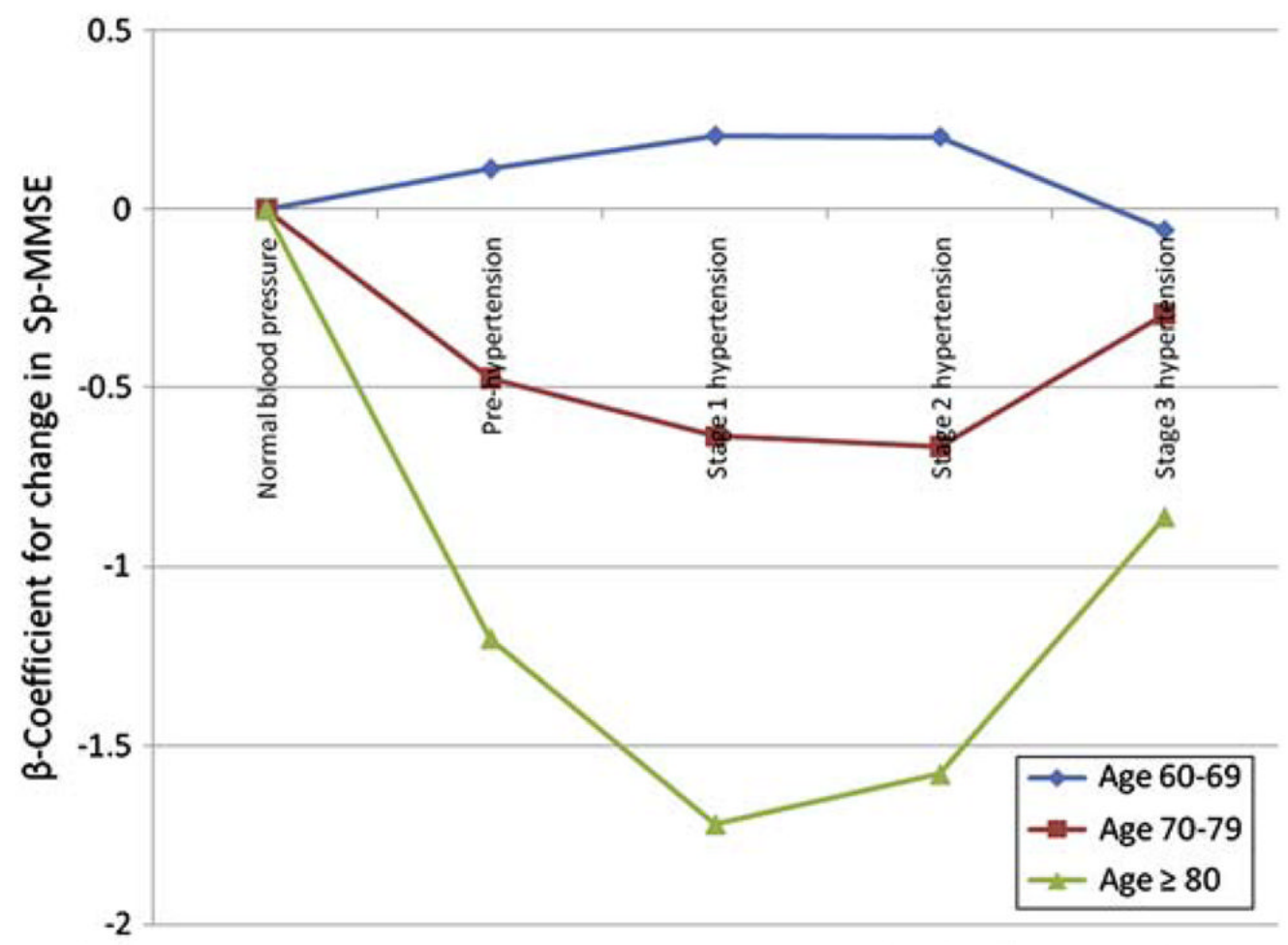

Fig. 4.

Age, gender, ethnicity, education, income, self-reported history of stroke and medication treatment, body mass index, glycosylated hemoglobin, and physical activity-adjusted change in short portable MMSE score according to JNC VI stages of blood pressure: The Third National Health and Nutrition Examination Survey (NHANES III).

Note: optimal and normal are collapsed as one group; Sp-MMSE means short protable minimental state examination. 

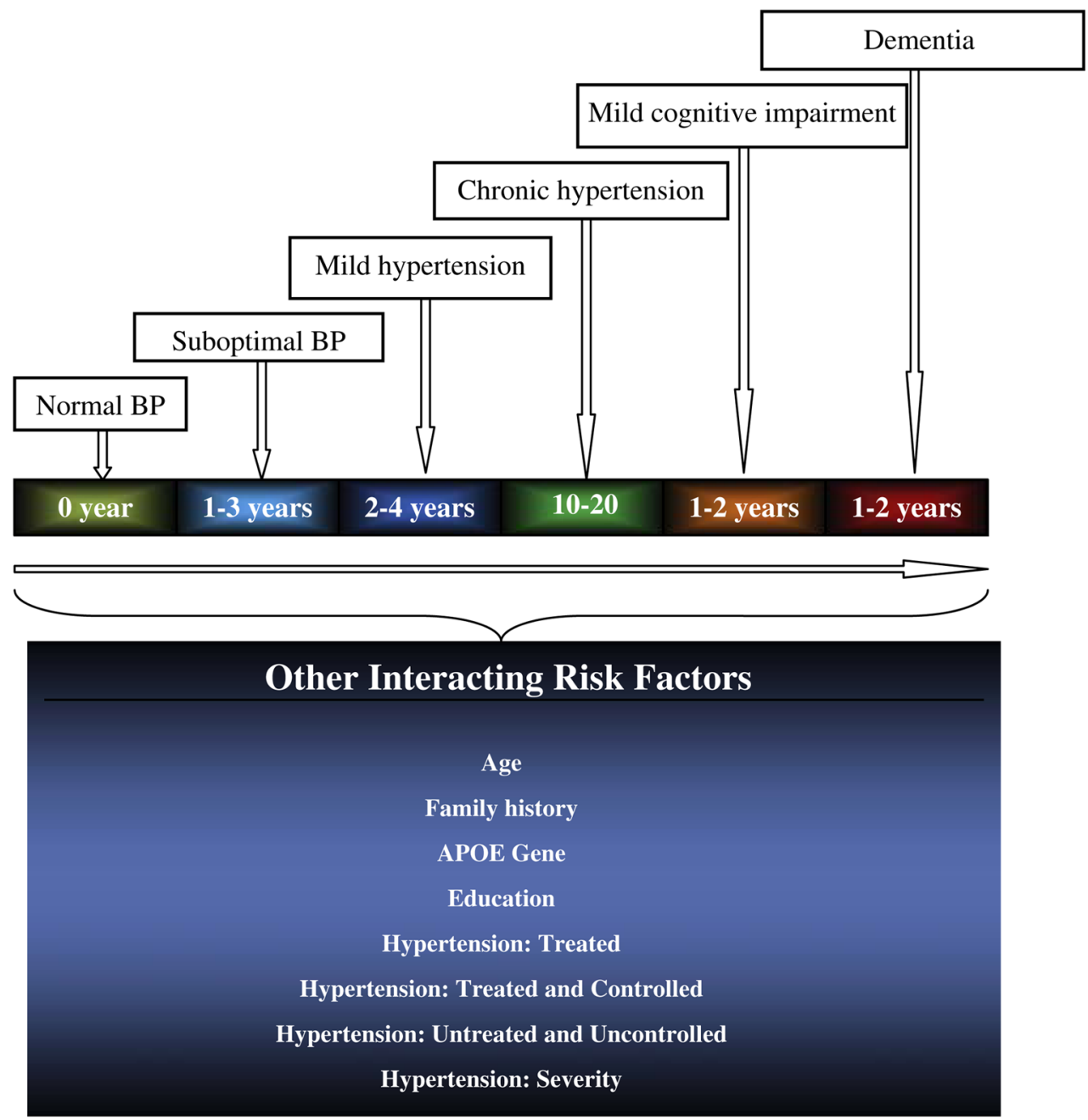

Fig. 5.

Time and sequence and interacting factors: Relationship of hypertension to future cognitive decline.

Note: From the beginning of sub-optimal blood pressure to hypertension-related cognitive loss, $\sim 15$ to 30 years may be required for its cognitive effects. Such effects will depend on the presence of other modifiers and or mediators such as: age, family history of AD, presence of APOE allele, gender, ethnicity, educational attainment, severity of hypertension, and whether or not hypertension is treated and or controlled. 


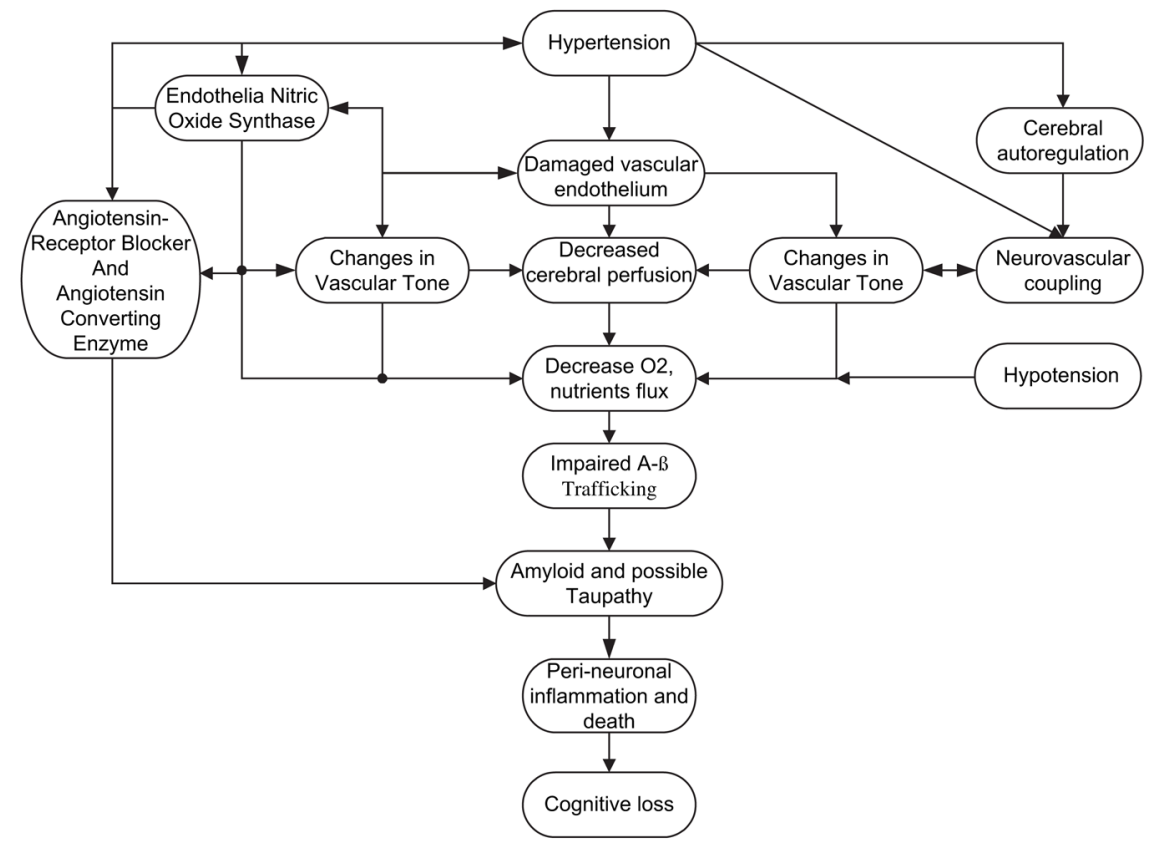

Fig. 6.

Mechanism by which hypertension affects cognitive function.

Note: Hypertension can cause direct damage to vascular endothelium and decrease cerebral perfusion. Hypertension-related alteration in cerebral autoregulatory mechanisms and neurovascular coupling can cause changes in vascular tone and reduce cerebral perfusion. Alternatively, direct hypertension-related damage to the endothelium may alter endothelia nitric oxide function with resultant change in vascular tone and cerebral hypoperfusion. Concomitant or hypertension-related changes in angiotensin receptor and or angiotensin converting enzyme can directly promote amyloid deposition as well as alter cerebral perfusion through changes in vascular tone. Below age-specific optimal blood pressure can directly reduce cerebral perfusion and promote chronic cerebral oxygen insufficiency, a common pathway by which hypertension-related $\beta$-amyloid pathology, peri-nueronal inflammation and consequent cognitive loss occurs. 
Table 1

Ranges for the various blood pressure categories

\begin{tabular}{|lrr|}
\hline & \multicolumn{2}{c|}{ Blood Pressure (mm Hg) } \\
\cline { 2 - 3 } Blood Pressure Categories & Systolic & Diastolic \\
\hline Optimal & $<120$ & $<80$ \\
\hline Normal & $120-129$ & $80-85$ \\
\hline Prehypertension & $130-139$ & $86-89$ \\
\hline Stage I hypertension & $140-159$ & $90-99$ \\
\hline Stage II hypertension & $160-179$ & $100-109$ \\
\hline Stage III hypertension & $\geq 180$ & $\geq 110$ \\
\hline
\end{tabular}

